\title{
Neurotrophin-4 Deficient Mice Have a Loss of Vagal Intraganglionic Mechanoreceptors from the Small Intestine and a Disruption of Short-Term Satiety
}

\author{
Edward A. Fox, ${ }^{1}$ Robert J. Phillips, ${ }^{2}$ Elizabeth A. Baronowsky, ${ }^{2}$ Mardi S. Byerly, ${ }^{1}$ Sarahlouise Jones, ${ }^{2}$ and \\ Terry L. Powley² \\ ${ }^{1}$ Behavioral Neurogenetics Laboratory and 'Laboratory of Regulatory Psychobiology, Department of Psychological \\ Sciences, Purdue University, West Lafayette, Indiana 47907
}

Intraganglionic laminar endings (IGLEs) and intramuscular arrays (IMAs) are the two putative mechanoreceptors that the vagus nerve supplies to gastrointestinal smooth muscle. To examine whether neurotrophin-4 (NT-4)-deficient mice, which have only $45 \%$ of the normal number of nodose ganglion neurons, exhibit selective losses of these endings and potentially provide a model for assessing their functional roles, we inventoried IGLEs and IMAs in the gut wall. Vagal afferents were labeled by nodose ganglion injections of wheat germ agglutinin-horseradish peroxidase, and a standardized sampling protocol was used to map the terminals in the stomach, duodenum, and ileum. NT-4 mutants had a substantial organ-specific reduction of IGLEs; whereas the morphologies and densities of both IGLEs and IMAs in the stomach were similar to wild-type patterns, IGLEs were largely absent in the small intestine (90 and $81 \%$ losses in duodenum and ileum, respectively). Meal pattern analyses revealed that NT-4 mutants had increased meal durations with solid food and increased meal sizes with liquid food. However, daily total food intake and body weight remained normal because of compensatory changes in other meal parameters. These findings indicate that NT-4 knock-out mice have a selective vagal afferent loss and suggest that intestinal IGLEs (1) may participate in short-term satiety, probably by conveying feedback about intestinal distension or transit to the brain, (2) are not essential for long-term control of feeding and body weight, and (3) play different roles in regulation of solid and liquid diet intake.

Key words: autonomic nervous system; food intake; meal pattern; gastrointestinal tract; intraganglionic laminar endings; knock-out mice; myenteric neurons; vagus nerve; visceral afferents
Vagal afferents are essential for CNS coordination of homeostasis. A subset of vagal afferents that have been implicated as key to gastrointestinal (GI) regulation and ingestive behavior consists of the two morphologically distinct classes of mechanoreceptors supplied to the muscle wall of the GI tract. One class is comprised of intraganglionic laminar endings (IGLEs) (Fig. 1) that innervate myenteric ganglia (Nonidez, 1946; Rodrigo et al., 1975, 1982; Neuhuber, 1987; Zagorodnyuk and Brookes, 2000) and are distributed throughout the GI tract (Fig. 1) (Fox et al., 2000; Wang and Powley, 2000). The other consists of intramuscular arrays (IMAs) that have a much more restricted distribution that is limited to the stomach and adjacent sphincters (Fig. 1). In particular, IMAs are concentrated in the circular or longitudinal muscle layers of the forestomach and lower esophageal and pyloric sphincters, where they form appositions with muscle fibers and/or interstitial cells of Cajal (Fig. 1) (Berthoud and Powley, 1992; Kressel et al., 1994; Fox et al., 2000, 2001; Wang and Powley, 2000). These vagal mechanoreceptors are thought to provide the CNS with negative feedback that is activated by

\footnotetext{
Received May 30, 2001; revised Aug. 3, 2001; accepted Aug. 14, 2001.

This work was supported by National Institutes of Health Grant DK27627. We thank Matt Adams, Matt Bruno, Camille Leamon, and Julia Tibbets for their contributions to the behavioral experiments, Marcy Boynton and Steve Foldes for histology, Jeff Mitchell for artwork, and Talal Karam for animal care.

Correspondence should be addressed to Dr. Edward A. Fox, Department of Psychological Sciences, Behavioral Neurogenetics Laboratory, Purdue University, 1364 Psychological Sciences Building, West Lafayette, IN 47907-1364. E-mail: au_gc@psych.purdue.edu.

Copyright (C) 2001 Society for Neuroscience $\quad 0270-6474 / 01 / 218602-14 \$ 15.00 / 0$
}

accumulation and movement of food in the stomach and intestine (Phillips and Powley, 2000) and may therefore be involved in regulation of feeding, especially in the control of meal size or short-term satiety.

Investigations into such afferent functions require independent manipulations of sensory and motor pathways. Two strategies have been developed to limit the degree of vagal motor damage, and results obtained with these methods have been consistent with a feedback role for vagal GI afferents. One approach involves systemic application of the excitotoxin capsaicin to selectively damage sensory neurons with unmyelinated axons (Carobi, 1996). When offered a novel diet, rats deafferented in this manner ate a larger meal than controls (Chavez et al., 1997). However, this overconsumption was transient, possibly because vagal afferents that remain intact compensate (Chavez et al., 1997; Schwartz et al., 1999). A second approach to sensory vagotomy involves cutting the sensory rootlets unilaterally as they exit the medulla and cutting one or more of the contralateral subdiaphragmatic vagal branches (Smith et al., 1985; Walls et al., 1995a), manipulations that only damage efferents unilaterally. Rats prepared in this manner exhibited a chronic increase in meal size (Schwartz et al., 1999).

An alternative strategy for selective elimination of vagal afferents that has not been pursued is a genetic approach. Loss-offunction mutations of individual neurotrophins produce losses of specific classes of peripheral sensory neurons without affecting motorneurons (Ernfors et al., 1994; Conover et al., 1995; Liu et al., 1995). Mice deficient in neurotrophin-4 (NT-4) are particu- 

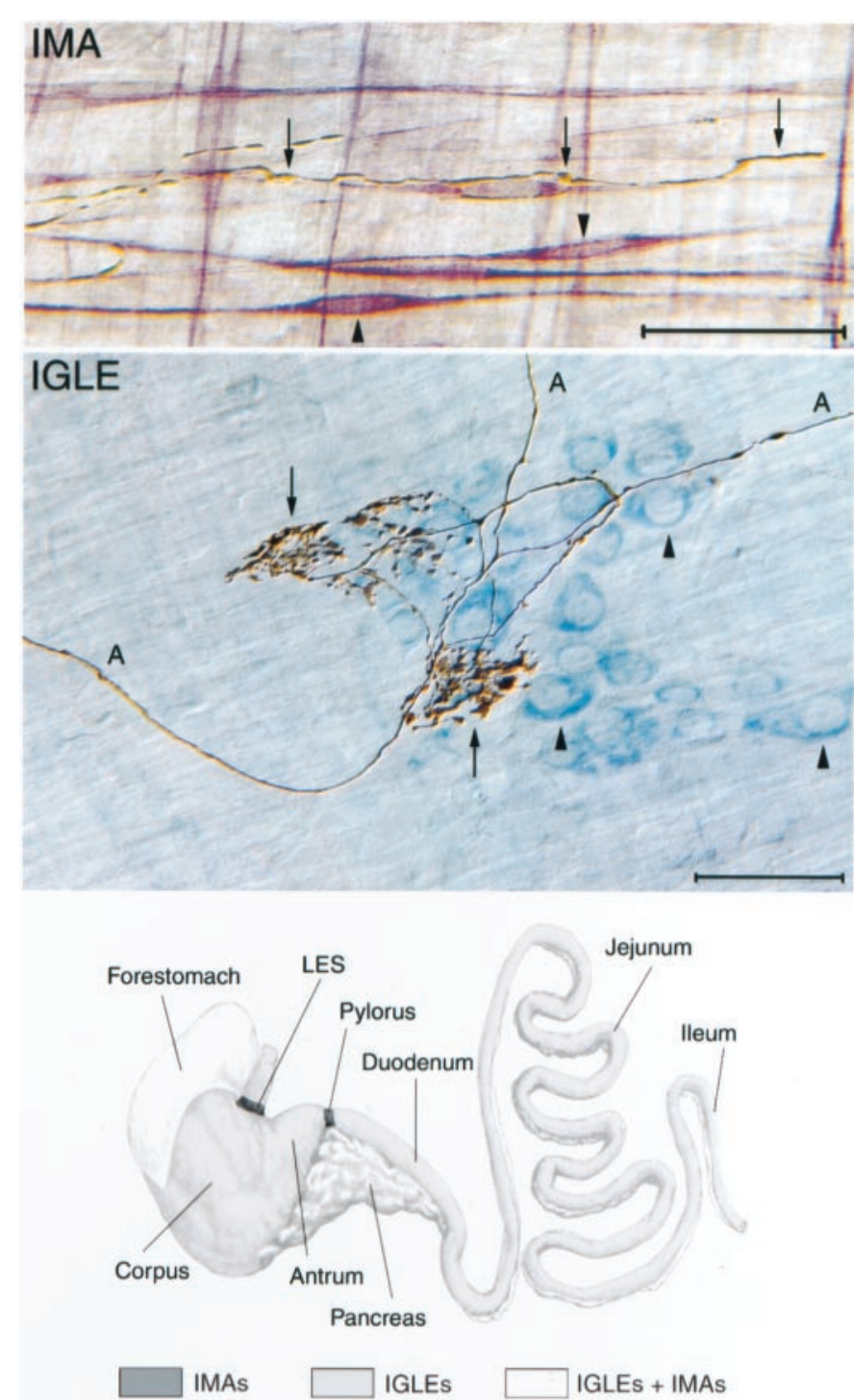

Figure 1. Structure and distribution of vagal IMA- and IGLE-type mechanoreceptors. Top, Photomicrograph of dual-stained tissue demonstrating the structure of the terminal portion of an IMA process (arrows) and its associations with smooth muscle and interstitial cells of Cajal of the intramuscular class (ICC-IMs) (arrowheads point to the cell bodies of two ICC-IMs). The terminal IMA process is golden brown (dextranbiotin tracer stained with DAB reaction) and as imaged here with Nomarski differential interference contrast optics; it also has a dark shadow. ICC-IMs are stained red-purple (antibody to c-Kit receptor tyrosine kinase and Vector VIP were used), and muscle fibers are not stained. The terminal IMA process enters from the left and is in close apposition to an ICC-IM. As this IMA process follows the contour of the ICC-IM, a small branch forms that wraps around the cell body of the ICC-IM (the cell body contains the nucleus, which is a pale, elongated oval structure near the center of the ICC-IM). The IMA process eventually bends away from the ICC-IM process to terminate on the adjacent muscle fiber (farthest arrow to the right). Scale bar, $50 \mu \mathrm{m}$. Middle, Photomicrograph of dualstained tissue demonstrating the structure of IGLEs and their association with myenteric ganglia. The IGLE axons $(A)$ and terminals (puncta) are stained in the same manner as described for the IMA terminal in the top panel. Myenteric neurons are light blue (cuprolinic blue stain; arrowheads), and muscle fibers are not stained. Each IGLE is composed of numerous, densely packed terminal puncta (boutons) that are distributed from a small number of terminal axon processes that weave through and around the aggregate of puncta (arrows). The terminal aggregate has laminar form (lies within a single plane) and covers a portion of one myenteric ganglion. These IGLE-myenteric ganglion interactions occur in the myenteric nerve plexus that larly attractive candidates. They lack $55 \%$ of vagal sensory neurons, yet they are viable (Conover et al., 1995; Liu et al., 1995), suggesting that the innervation arising from these neurons is not critical to survival and therefore may include vagal afferents that supply the GI tract. Moreover, consistent with the probability that mechanoreceptors are among the vagal afferents affected by the absence of NT-4, the only somatosensory pathway largely dependent on NT-4 for survival supplies mechanoreceptors (cutaneous D-hair afferents) (Stucky et al., 1998). Therefore, the present study investigated the status of vagal GI mechanoreceptors in NT-4 mutant and wild-type mice. Food intake patterns were also characterized to examine the suspected role of vagal mechanoreceptor signaling in ingestive behavior.

Parts of this paper have been presented previously at the annual meeting of the Society for Neuroscience (Nov. 4-9, 2000; New Orleans, LA) (Fox et al., 2000).

\section{MATERIALS AND METHODS}

\section{Animals}

Male wild-type mice (129S3/SvImJ; +/+) and NT-4 mutant mice (129S4/ SvJae-Ntf5 ${ }^{\text {tmlJae}}$; $-/-$ ) weighing $20-25 \mathrm{gm}$ and 2-4 months of age were obtained from The Jackson Laboratory (Bar Harbor, ME). Animals were housed individually, maintained on a $12 \mathrm{hr}$ light/dark schedule at $23^{\circ} \mathrm{C}$, and given ad libitum access to tap water and pellets (Laboratory Rodent Diet 5001; PMI Nutrition International, St. Louis, MO). All procedures were conducted in accordance with the National Institutes of Health's Principles of Laboratory Animal Care (publication no. 86-23, revised 1985) and American Association for Accreditation of Laboratory Animal Care guidelines and were approved by the Purdue University Animal Care and Use Committee.

\section{Tracer injections into the nodose ganglion}

Wheat germ agglutinin-horseradish peroxidase (WGA-HRP; Vector Laboratories, Burlingame, CA) that was injected into the nodose ganglion (Aldskogius et al., 1986) was used to map and quantify the distributions of IMAs and IGLEs in the stomach and intestine. This method is specific for labeling gastrointestinal sensory vagal terminations, and it labels virtually all of them (for discussion, see Phillips et al., 1997; Fox et al., 2000; Wang and Powley, 2000). Nodose ganglion injections were performed as previously described (Fox et al., 2000). Briefly, mice were anesthetized intraperitoneally with ketamine-xylazine, and the left or right nodose ganglion was exposed. Then, $4 \%$ WGA-HRP was pressureinjected through a glass micropipette into the ganglion. Mutant and wild-type mice were always injected, perfused, and processed in parallel to control for any inadvertent variations in these procedures.

\section{Preparation of whole mounts of the stomach, duodenum, and ileum}

Twenty-two hours after the nodose injection, each animal was deeply anesthetized and perf used with fixative as described (Fox et al., 2000). In short, $20 \mathrm{U}$ of heparin sodium and $0.02 \mathrm{mg}$ of propranolol hydrochloride were injected into the left ventricle. Next, animals were perfused transcardially with $0.9 \%$ saline at $40^{\circ} \mathrm{C}$, their stomachs were expanded with $0.9 \%$ saline at $35^{\circ} \mathrm{C}$, and then the tissues were perfused with chilled $3 \%$ paraformaldehyde $/ 0.75 \%$ gluteraldehyde.

Stomachs and intestines were prepared as whole mounts (Powley et al.,

\section{$\leftarrow$}

lies between the longitudinal and circular smooth muscle layers of the GI tract wall. Scale bar, $50 \mu \mathrm{m}$. Bottom, Schematic diagram of the stomach (left) and small intestine (right), with their standard subdivisions identified. The pancreas is also illustrated, but contains no IMA- or IGLE-type mechanoreceptors. IGLEs are distributed throughout the esophagus, stomach, and intestine with the exception of the lower esophageal sphincter $(L E S)$ and pylorus regions. Only IMAs are found in the LES and pylorus regions. Both IGLEs and IMAs are present in the forestomach in which their distributions overlap extensively. Only IGLEs are found in the corpus and antrum of the stomach and in the small intestine (duodenum, jejunum, and ileum). 

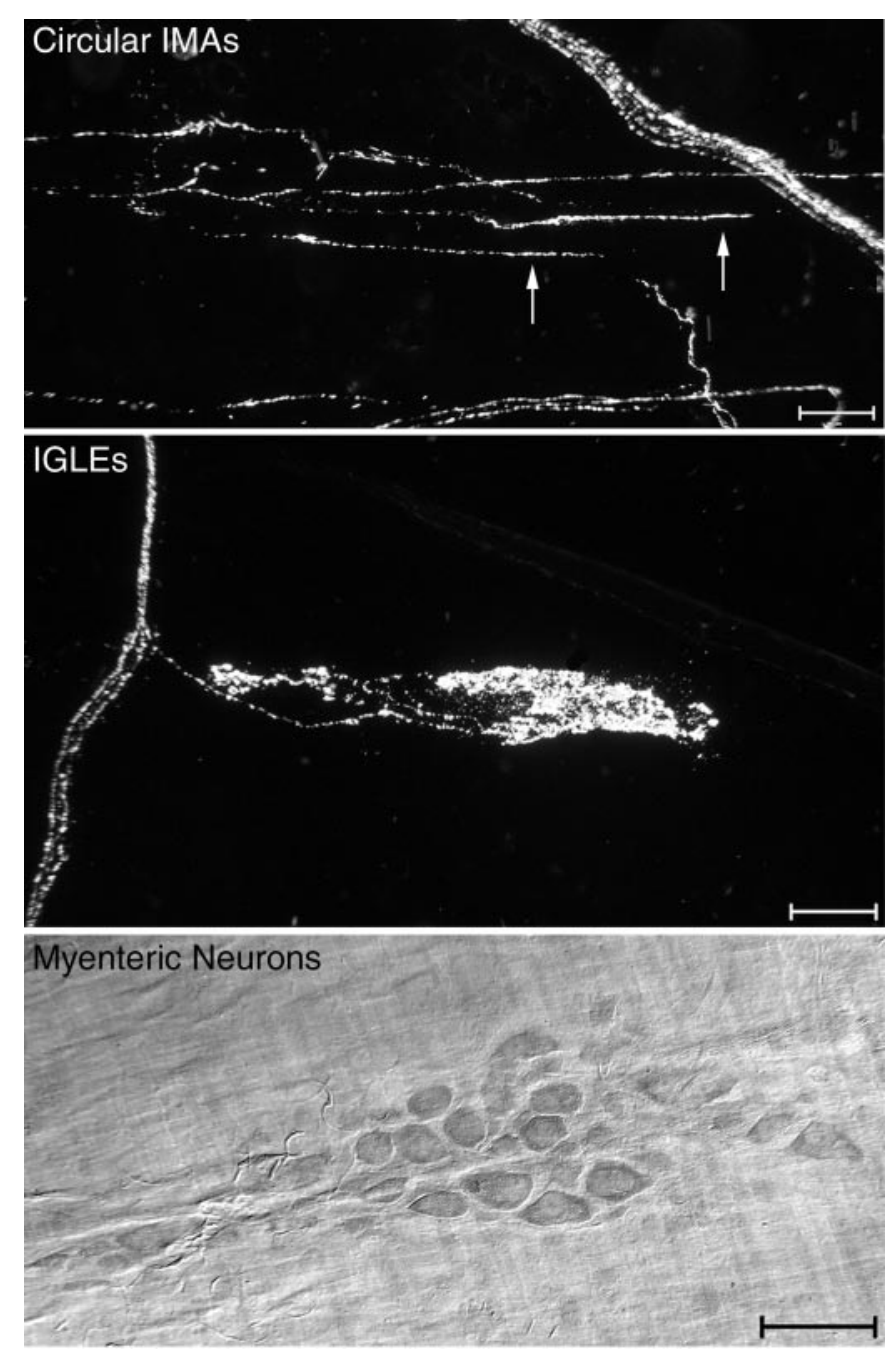

Figure 2. Neural elements that were quantified included circular IMAs, IGLEs, and myenteric neurons. Top, A darkfield photomicrograph from the forestomach of a wild-type mouse. Three parallel telodendria (oriented horizontally; two of the parallel telodendria are identified by arrows) are connected by crossbridges to form one IMA (labeled with WGA-HRP) within the circular muscle layer. A small bundle of labeled sensory axons (oriented diagonally) is present in the top right portion of the image. Middle, A darkfield photomicrograph of an IGLE from the duodenum of a wild-type mouse labeled with WGA-HRP. The IGLE extends horizontally from a small sensory axon bundle that is oriented vertically at the left of the image. Bottom, A brightfield photomicrograph of a myenteric ganglion from the duodenum. Myenteric neurons in wholemounted GI tract regions were stained with cuprolinic blue. Scale bars, 50 $\mu \mathrm{m}$.

1994). In brief, the GI tract was rinsed with cold tap water and then separated into stomach-esophagus, duodenum, and ileum. The entire stomach (along with the subdiaphragmatic portion of the esophagus), the first $8 \mathrm{~cm}$ of the duodenum, and the $5 \mathrm{~cm}$ length of ileum that lies immediately anterior to the ileocecal junction were isolated. The stomach-esophagus was divided into dorsal and ventral halves by cutting along the greater and lesser curvatures. The duodenum was divided into two 4 $\mathrm{cm}$ lengths, and then these tissues and the $5 \mathrm{~cm}$ length of ileum were each opened with a longitudinal cut along the mesenteric attachment. Sharp dissection was used to separate the muscular layers from the mucosal and submucosal layers. Whole mounts of the muscle layers labeled with WGA-HRP were processed with tetramethyl benzidine according to the protocol of Mesulam (1978) and then mounted, dried, cleared, coverslipped as described (Fox et al., 2000), and examined with dark-field illumination (Leitz Orthoplan II microscope).

\section{Quantification of vagal sensory terminals and axon bundles}

NT-4 mutant (129S4/SvJae-Ntf5 tmlJae $-/-; n=6$, right nodose injection; $n=4$, left nodose injection) and wild-type (129S3/SvImJ $+/+; n=6$, right nodose injection; $n=4$, left nodose injection) mice that met the criteria for inclusion were used to quantify the distributions of IGLEs in the duodenum. Additionally, IMAs in the circular muscle layer of the stomach and IGLEs in the stomach and ileum were quantified in animals with right nodose injections that met the criteria for inclusion. Cases were excluded from formal quantitative analyses if HRP-labeled terminals were obscured in some regions of the stomach or intestine by any of the forms of artifact that can be produced by the peroxidase reaction (Mesulam, 1978). Animals were also excluded when an absence of labeled fibers occurred in a portion of the stomach wall, indicating that tracer injection into the nodose was incomplete. In all control animals to date, in several strains of mice, the degree of intestine innervation labeled has been highly correlated with completeness of stomach labeling. All counts were made by the same individual who was blind to genotype.

Criteria for counting. Intraganglionic laminar endings and IMAs are the two major terminal specializations of vagal afferents innervating the smooth muscle wall of the mouse and rat GI tracts (Rodrigo et al., 1982; Neuhuber, 1987; Berthoud and Powley, 1992; Fox et al., 2000; Wang and Powley, 2000). Each afferent ending type was identified by dual criteria based on both morphology and location (types of stomach elements they associate with). The criteria for counting an ending as an IGLE were that it consisted of (1) a laminar (2) aggregate of fine terminal puncta, (3) within the neuropil of a myenteric ganglion and (4) covering all or part of the ganglion (Fig. 2) (Rodrigo et al., 1975, 1982; Neuhuber, 1987). The criteria for counting an ending as an IMA (Berthoud and Powley, 1992; Fox et al., 2000; Wang and Powley, 2000) were that it consisted of (1) parallel axonal telodendria (2) in close proximity, (3) interconnected by bridging axonal elements and (4) located in either the longitudinal or circular muscle layer (Fig. 2).

Sampling. To facilitate a quantitative reconstruction of the vagal afferent innervation of the GI tract (as well as to facilitate comparison across experiments), a standardized sampling procedure was used (Fox et al., 2000). Briefly, a sampling grid was used to locate areas to be quantified, and then a counting grid was positioned at each of these preselected areas and used to count the number of endings at each sampling location. The sampling grid used sliding scales to normalize each whole-mounted stomach half so that the variability attributable to differences in stomach size or distension was minimized. This strategy resulted in sampling all stomach halves at 48 similar areas, with $13 \%$ of the area of each whole mount sampled. In contrast, the entire muscle wall of each duodenum and ileum whole mount was sampled for IGLEs that were labeled with WGA-HRP because their density was very low in mutants. Sensory axon bundles were sampled in the NT-4 mutants $(n=4)$ and wild-type mice $(n=4)$ with left nodose injections. Counts were made every $5 \mathrm{~mm}$ along the length of the first $3 \mathrm{~cm}$ of the duodenum adjacent to the pylorus. At each of these anterior-posterior levels, seven regions were sampled that were equidistant across the width of the duodenum.

Counting. Counting was done at a final magnification of $80 \times$ using a camera lucida drawing arm to merge an image of a counting grid $\left(1 \mathrm{~mm}^{2}\right)$ with the tissue image in the microscope. The counting grid consisted of $9 \times 9$ equidistant lines (forming 64 squares) and was rotated to align one set of lines with circular muscle and the perpendicular set with longitudinal muscle. IGLEs and IMAs were counted as previously described (Fox et al., 2000). The density of sensory axon bundles was estimated by counting the total number of intersections that axon bundles made with the grid lines at each sampling location.

\section{Myenteric neuron counts}

Staining of myenteric neurons. Wild-type (129S3/SvImJ $+/+; n=4)$ and NT-4 mutant (129S4/SvJae-Ntf5 $\left.5^{\text {tmlJae }}-/-; n=4\right)$ mice were used only for obtaining myenteric neuron counts. The cuprolinic blue method for staining myenteric neurons was chosen because it is specific for neurons and it appears to label the most inclusive population of myenteric neurons of any single marker with a variety of fixatives (Heinicke et al., 1987; Karaosmanoglu et al., 1996). For this procedure, whole mounts of GI tract tissues from animals prepared as described above for WGAHRP processing were used. Cuprolinic blue (quinolinic phthalocyanine; catalog \#17052; Polysciences, Warrington, PA) staining was performed essentially as described (Holst and Powley, 1995), except that whole mounts were incubated in cuprolinic blue solution for $4 \mathrm{hr}$.

Sampling and counting. After cuprolinic blue staining, individual my- 
Table 1. Estimated number of neurons in the nodose ganglia in wild-type $(n=9)$ and NT-4 mutant $(n=$ 9) mice and percentage of cell loss in mutants

\begin{tabular}{lllll} 
& Wild-type $(+/+)$ & Mutant $(-/-)$ & Cell loss $(\%)$ & $p$ value \\
\hline Right nodose & $2468 \pm 106$ & $1140 \pm 112$ & 54 & $<0.05$ \\
Left nodose & $2203 \pm 233$ & $913 \pm 143$ & 59 & $<0.05$ \\
\hline
\end{tabular}

Mean \pm SEM; see Materials and Methods for calculations.

enteric neurons are distinct with blue-stained Nissl substance clearly outlining the nucleus (which is unstained) and a stained nucleolus (Fig. 2). Myenteric glial cells are not known to be stained by this method; therefore, all of the stained cells were considered neuronal. Areas with excessive folds or tears were excluded. The fitted-grid and counting-grid strategies described above for WGA-HRP-labeled nerve terminals in the stomach were used for sampling myenteric neurons that were stained with cuprolinic blue in whole mounts of the dorsal and ventral stomach, duodenum, and ileum. In the intestine, this entailed counting within transverse-sampling bands situated every $5 \mathrm{~mm}$ along the length of the tissue (one counting grid length $=1 \mathrm{~mm}$ ). Cells within the boundaries of the grid and those that transected the left and bottom gridlines were counted, whereas those traversing the top or right gridlines were excluded.

\section{Nodose ganglion cell counts}

After perfusion fixation, right and left nodose ganglia were removed from animals with left nodose ganglion injections of WGA-HRP (wildtype, $129 \mathrm{~S} 3 / \mathrm{SvImJ}+/+, n=9$; NT-4 mutant, $129 \mathrm{~S} 4 / \mathrm{SvJae}-\mathrm{Ntf5} 5^{\text {tmlJae }}$ $-/-, n=9)$. The ganglia were embedded in paraffin, sectioned at $10 \mu \mathrm{m}$ thickness, and stained with cresyl violet. For each ganglion, neurons that contained nucleoli were counted at $200 \times$ magnification (and inspected at $320 \times$ when necessary) in equidistant sections that spanned the entire ganglion. The initial section that was counted was randomly selected from the first 10 sections that contained neurons, and one-tenth of the total number of sections encompassing a ganglion was counted. Counting was performed blind to genotype. The raw counts that were obtained were used to estimate the total number of neurons in each ganglion as the product of the mean neuron number per sampled section and the total number of sections. Consideration of the potential for bias in these estimates (Coggeshall and Lekan, 1996; Guillery and Herrup, 1997) has been discussed elsewhere (Fox et al., 2001).

\section{Dorsal motor nucleus cytoarchitecture}

A subset of wild-type (129S3/SvImJ $+/+, n=2)$ and NT-4 mutant $\left(129 \mathrm{~S} 4 / \mathrm{SvJae}-\mathrm{Ntf5} 5^{\text {tmIJae }}-/-, n=3\right)$ mice injected in the right or left nodose ganglion with WGA-HRP were used to assess the status of the dorsal motor nucleus of the vagus nerve that contains the vagal preganglionic neurons that innervate the upper GI tract. After perfusion, the brainstems of control and mutant animals were removed, post-fixed in formalin for at least $48 \mathrm{hr}$, and then cryoprotected by an overnight incubation in 0.1 M PBS containing 30\% sucrose. Cryosections of brainstem were cut at $28 \mu \mathrm{m}$, and every other section was collected on gelatin-coated slides and stained with cresyl violet.

\section{Meal pattern-microstructure analysis}

Wild-type (129S3/SvImJ $+/+; n=15$, solid food; $n=12$, liquid food) and NT-4 mutant (129S4/SvJae-Ntf5 tmIJae $-/-; n=15$, solid food; $n=12$, liquid food) mice were used in a meal pattern analysis designed to provide a broad assessment of vagal sensory functions. Mutant and wild-type mice were tested in parallel to control for any inadvertent variations in the testing conditions. Balanced solid $(20 \mathrm{mg}$ dustless precision pellets; Bio-Serv, Frenchtown, NJ) and liquid (Isocal; Mead Johnson, Evansville, IN) diets were delivered using an automated pellet dispenser or a liquid dipper, respectively (Coulbourn Instruments, Inc., Allentown, PA). Each delivery mechanism was activated when an animal's response changed the state of a photo beam (broken or unbroken). Graphic state software (v. 1.011; Coulbourn Instruments, Inc.) was used to program all feeding and drinking apparatus and to record the occurrence and time of each change in photo beam state that indicated an animal's response. Test cages were fashioned from standard mouse polycarbonate shoebox cages. Mice were adapted to the test room and test cages for 1 week before testing. During that week animals to be tested on the solid diet received three pre-exposures to the test diet (10 pellets per exposure) to prevent neophobia. Intake patterns were monitored $18 \mathrm{hr}$ a day, and animals were fasted the remaining $6 \mathrm{hr}$ of each day to examine the effects of moderate deprivation on the initial meal of each $18 \mathrm{hr}$ feeding session. Each daily session began at the start of the dark phase (12 hr light/dark cycle) and extended $6 \mathrm{hr}$ into the light phase. Meal pattern data were collected for 14 consecutive days to allow development and maintenance of stable feeding patterns. Meal initiation was defined as a minimum of seven pellet removals or seven dipper activations with $<20$ min elapsing between responses. Once a meal was initiated, meal termination was defined as $20 \mathrm{~min}$ with no intake.

\section{Statistical analysis, graphical display of data and photomicrography}

Hypotheses about differences between intestinal receptor and myenteric neuron populations and nodose ganglion neurons in mutants and wildtype mice were tested with an unpaired $t$ test; $p<0.05$ was required for statistical significance (Graphpad Prism Version 3.0; Graphpad Software, San Diego, CA). Graphpad was also used to construct bar graphs. Statistical differences in gastric receptor populations and myenteric neurons were tested using a repeated measures (repeated across GI compartments) ANOVA, and changes in food intake parameters were tested using repeated measures (repeated over days) ANOVA (Statistica, v5.0; StatSoft, Tulsa, OK) with $p<0.05$ required for statistical significance. Photomicrographs were acquired directly with a video camera (Spot RT Slider; Diagnostic Instruments, Sterling Heights, MI). Photoshop software (v5.5; Adobe Systems, Mountain View, CA) was used to (1) apply scale bars and text, (2) adjust brightness and contrast, and (3) organize the final layouts for printing. Images were printed using a Kodak Professional 8670 PS thermal printer (Eastman-Kodak, Rochester, NY).

\section{RESULTS}

\section{NT-4-deficient mice have a sensory-specific loss of vagal neurons}

Dramatic loss of vagal sensory neurons in NT-4-deficient mice

On embryonic day 18.5 (E18.5) and at, or soon after, birth, the nodose ganglia of NT-4-deficient mice exhibit a 50-60\% cell loss (Conover et al., 1995; Liu et al., 1995; Erickson et al., 1996). It has not been previously determined, however, whether this loss increases postnatally or whether it remains stable. The neuronal counts for the ganglia of the adult NT-4 mice in the present study (Table 1; Fig. $3 A, B$, nodose cresyl violet) demonstrated that this embryonic cell loss appears to remain stable postnatally, because the absolute numbers were similar and the percentage loss was almost identical to those reported for neonatal animals of the same knock-out strain (Liu et al., 1995).

\section{Vagal preganglionic neurons are intact in NT-4-deficient mice}

In general, losses of cells in the peripheral nervous systems of mice lacking a single neurotrophin, including NT-4, have proven to be sensory-specific in that particular classes of primary sensory neurons are affected, whereas motorneurons that innervate the same tissues are typically spared (Ernfors et al., 1994; Jones et al., 1994; Conover et al., 1995; Liu et al., 1995). However, the survival of vagal preganglionic neurons has not been previously examined in NT-4 mutants. Most of the parasympathetic motorneurons that innervate the upper digestive tract are located in the dorsal motor nucleus of the vagus nerve $(\mathrm{dmnX})$. Inspection of the cross sections of the medulla in a small sample of cases did not reveal 

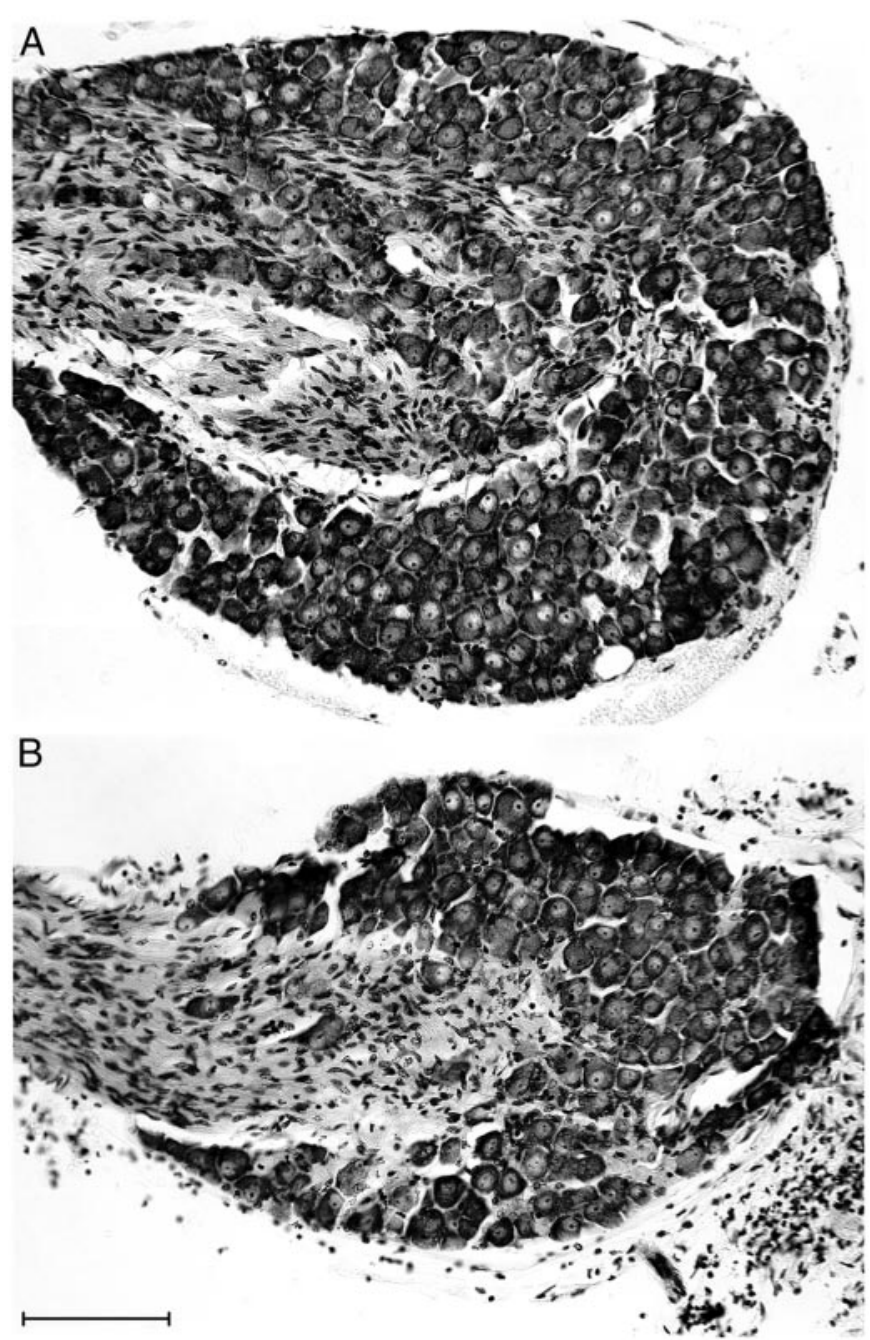

Figure 3. Neuron loss in the nodose ganglia of NT-4 mutants. Photomicrographs of paraffin sections of nodose ganglia stained with cresyl violet from a wild-type mouse $(A)$ and an NT-4 mutant mouse $(B)$ illustrate the sensory neuron loss (on average, 57\%) observed in the mutants. The vagus nerve enters the ganglia from the left in these images, as indicated by the stained Schwann cells. Scale bar, $100 \mu \mathrm{m}$.

a loss of dmnX motorneurons (Fig. 4), although we cannot exclude the possibility that a subtle change would be detected with a more extensive and quantitative survey.

The $57 \%$ loss of afferent neurons in the nodose ganglion, combined with no apparent loss of vagal preganglionic neurons in the dmnX, suggests that the vagal lesion that results from deficiency of NT-4 is sensory-specific.

\section{NT-4 knock-out produced loss of vagal mechanoreceptors that is specific to IGLEs and to the intestines}

NT-4 knock-out has no significant effect on stomach IGLEs

IGLEs form a continuous network of sensory nerve terminals that innervate ganglia throughout the myenteric plexus of the esophagus, stomach, and intestine, a network that is only interrupted for short distances in the vicinity of major sphincters. In our previous characterization of IGLEs in several strains of mice (Fox et al. 2000), including 129 wild-type mice, we found that they consist of laminar aggregates of numerous, fine terminal puncta that encapsulate all or part of a myenteric ganglion. We also
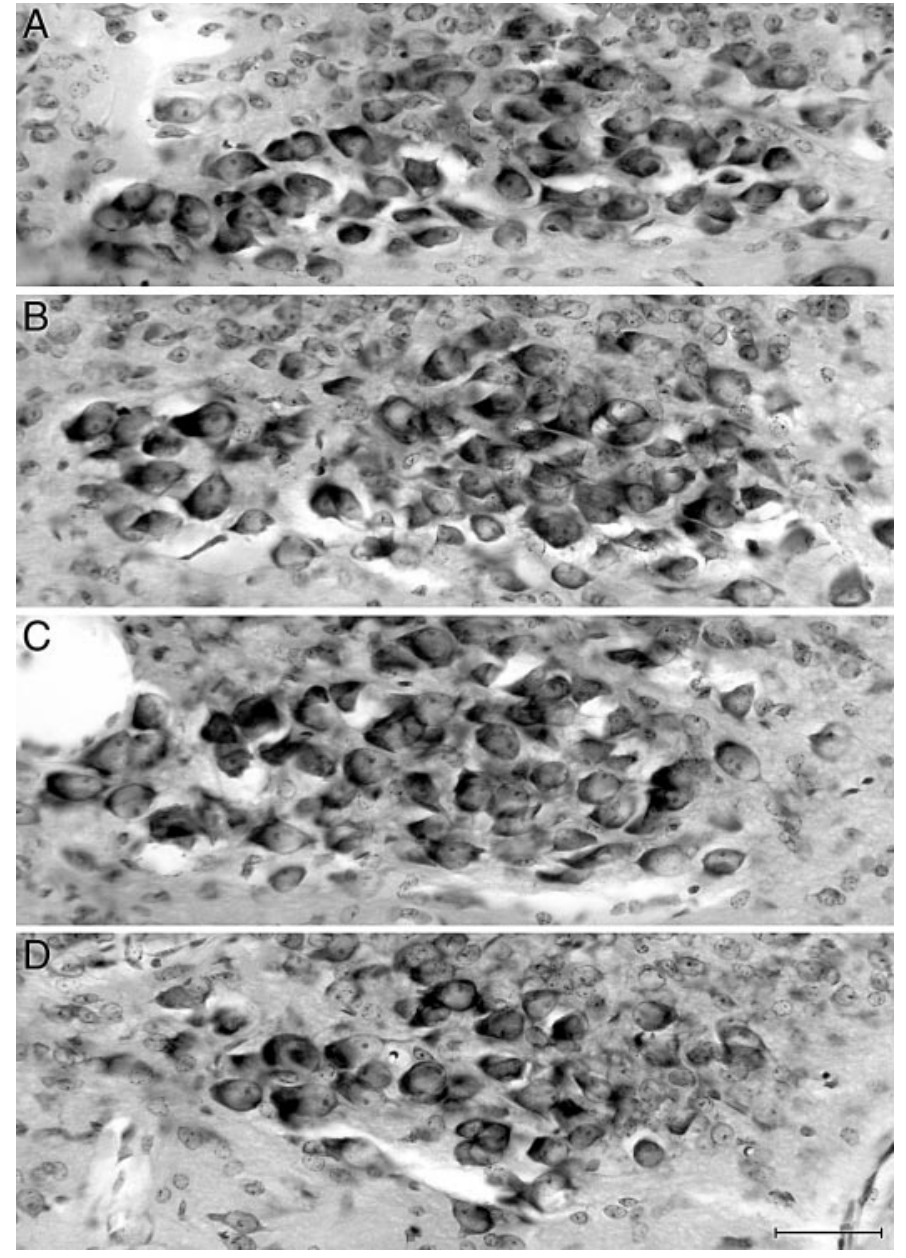

Figure 4. There was no significant loss of vagal preganglionic neurons in the dorsal motor nucleus of the vagus (dmnX). Photomicrographs of the longitudinal column of neurons that forms the $\mathrm{dmnX}$ on one side of the dorsomedial medulla in coronal sections stained with cresyl violet (medial is to the right and dorsal is toward the top of each image). The dmnX consists of dark-stained medium-sized neurons that form a spindleshaped nucleus in cross section, especially at mid-longitudinal levels $(C)$. As shown in $D$, the dmnX tapers at caudal levels so that its medial-lateral extent is reduced. The fourth ventricle $(A, B)$ or central canal $(C, D)$ is located out of view medial to each image. Comparison of these images of the dmnX from a wild-type mouse $(A)$ and an NT-4 mutant mouse $(B-D)$ illustrates the normal cytoarchitecture and neuron density of vagal preganglionic neurons that were observed in mutants. $A$ (wild type) and $B$ (NT-4 mutant) are from similar levels of the dmnX slightly anterior to the level of the area postrema, whereas $C$ (NT-4 mutant) is from the mid-area postrema level, and $D$ (NT-4 mutant) is from the caudal area postrema level. The unstained circular region at the lateral edge of the $\mathrm{dmnX}$ in $C$ is a cross-sectioned blood vessel, an element that is often present in this region of the dmnX. Scale bar, $50 \mu \mathrm{m}$.

found that IGLEs are relatively evenly distributed across the forestomach, corpus, antrum, and proximal small intestine. Therefore, IGLE densities in the several compartments of the stomach were examined to determine whether gastric IGLEs are affected by NT-4 deletion. In both the wild-type and NT-4 mutant mice, the morphology and distributions of IGLEs in the forestomach, corpus, and antrum were very similar to each other and to those previously observed in other mouse strains (Fox et al., 2000). IGLE density was also quantitatively similar in mutants and controls in each of the three stomach regions, although there was a nonsignificant trend in NT-4 mutants toward decreased 

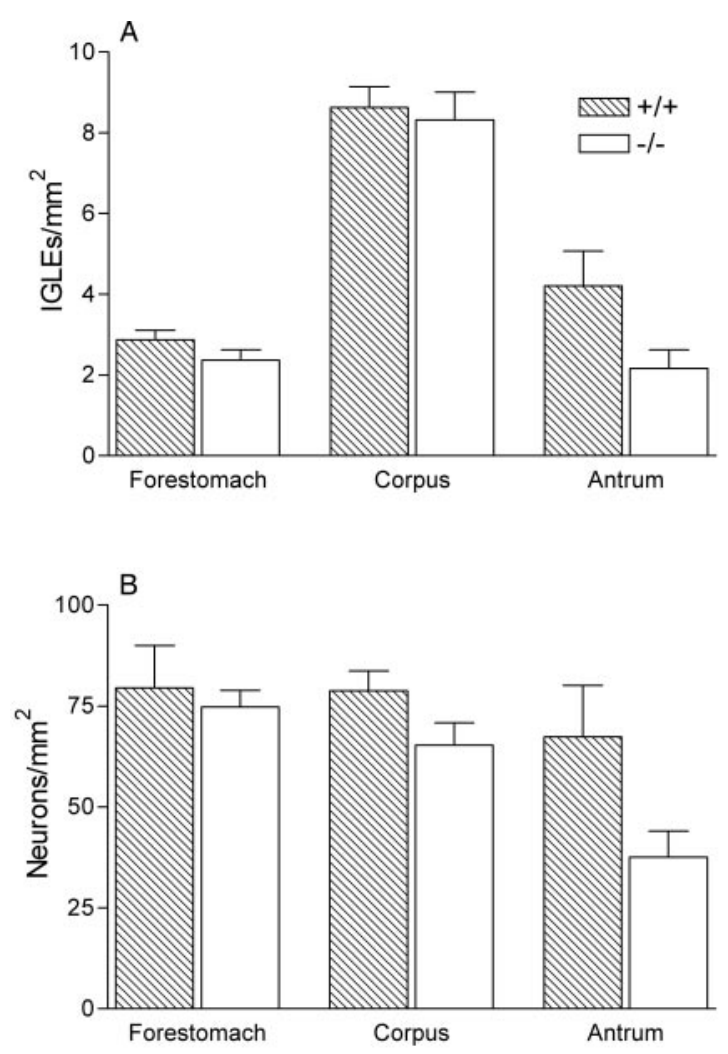

Figure 5. IGLE and myenteric neuron densities in the stomach were similar in wild-type and NT-4-deficient mice. Graphs of counts of IGLEs $(A)$ in the dorsal wall of each stomach compartment (forestomach, corpus, and antrum) and myenteric neurons $(B)$ in each stomach compartment (neuron counts were pooled from both the dorsal and ventral walls of the stomach because these counts were not significantly different in any of the stomach compartments). There were no significant differences between mutants and controls in any of the stomach compartments (two-way ANOVA with repeated measures over GI compartment; IGLEs, genotype $\times$ compartment, $p=0.18$; myenteric neurons, genotype $\times$ compartment, $p=0.36$ ).

IGLE density in the antrum, the most distal stomach compartment $(50 \%)$ (Figs. 5A, 6).

\section{NT-4 deficiency does not affect vagal intramuscular-type mechanoreceptors in the stomach}

To ascertain whether NT-4 deficiency affected IMA-type vagal mechanoreceptors, the other major vagal sensory terminal type found in the muscle wall of the stomach, we compared the morphology, distribution, and regional densities of IMAs in wildtype and NT-4 mutant mice. In our previous characterization of IMAs in several strains of mice (Fox et al., 2000), including 129 wild-type mice, we found that IMAs consisted of variable length telodendria (long rectilinear nerve terminal processes of an IMA receptor) that ran parallel to either circular (referred to as circular IMAs) (Fig. 2, top panel) or longitudinal (referred to as longitudinal IMAs) (Fig. 1, top panel) smooth muscle fibers. Typically, all of the associated telodendria that formed a wildtype IMA ran in the same direction and often they were interconnected by oblique or perpendicular crossbridge fibers. In the present study, we determined that IMA morphology (Fig. 7, compare $A, B)$ and density ( $p=0.67$ ) (Fig. $7 C$ ) were similar in wild-type and mutant mice. IMA distributions in both groups were also similar to each other and to those previously described in mouse strains, including the 129 strain (data not shown) (Fox et al., 2000). These results suggest that the absence of NT-4 during development does not impair the differentiation or survival of either of the two major classes of vagal mechanoreceptors that supply the stomach.

\section{NT-4-deficient mice exhibit almost complete loss of IGLEs in the small intestine}

In contrast to the sparing of the gastric mechanoreceptor populations, intestinal mechanoreceptors were largely eliminated by NT-4 deficiency. Basically, although the number of endings was altered, the overall distributions of IGLEs in the duodenum were similar to those observed previously in wild-type mice, and they were similar in the wild-type and NT-4 mutant animals. Because the left and right nodose ganglia have been shown to give rise to topographically distinct, although partially overlapping, IGLE populations in the duodenum and because these projections may exhibit other laterality effects [unlike the vagal projections to the stomach that for the most part are symmetrical (Berthoud et al., 1997a; Fox et al., 2000; Wang and Powley, 2000)], we examined intestinal innervation patterns in separate groups of animals with left and right nodose injections.

In the case of animals with left nodose injections, intraganglionic laminar endings were located throughout the $4 \mathrm{~cm}$ of the duodenum examined but were more concentrated in the anterior 1-2 cm (data not shown). However, the numbers of IGLEs were dramatically reduced in mutants as compared with wild types (90\%; $p<0.0001)$ (Figs. 8A, $B, 9 A)$. In the NT-4 mutants, the small number of IGLEs present were normal in morphology except that they appeared to be reduced in surface area to about half that observed in wild types (Fig. 10A,B).

The pattern of results in mice with right nodose ganglion injections of WGA-HRP replicated and extended the findings with left nodose injections. The overall pattern of topographic organization of IGLEs in the duodenum was similar in NT-4 mutants and wild types. Consistent with previous observations in other strains of mice (Fox et al., 2000) and rats (Wang and Powley, 2000), the IGLE density was much lower in the most proximal duodenum in both mutants and controls with right nodose injections, compared with left nodose injections (Fig. 9A). Intraganglionic laminar endings were located throughout the $8 \mathrm{~cm}$ of the duodenum examined and were more evenly distributed throughout the length of the duodenum as compared with left nodose injections (data not shown). Nevertheless, there was a substantial decrease in IGLE innervation of the duodenum in mutants with right nodose ganglion injections $(90 \% ; p=0.0031)$ (Fig. 9A). In conjunction with the previous findings for the stomach, the dramatic reduction of endings in the duodenum suggests that the loss of IGLEs is restricted to the small intestine and therefore is organ-specific.

An additional experiment was performed to address the concern that a deficit in the rate of axonal transport of WGA-HRP in mutants could produce an apparent decrease in innervation of a more distal organ (duodenum) as compared with normal innervation of a more proximal organ (stomach), when in fact its innervation density is also normal. To address this possibility, the ileum, which is distal to the duodenum, was also sampled for IGLEs in the mutant and wild-type mice that were injected in the right nodose ganglion. WGA-HRP-labeled IGLEs with normal structure were present in the ileum of both mutants and wild types, although again there was a reduction in the number of IGLEs in NT-4-deficient mice $(81 \% ; p=0.0002)$ (Fig. 9B). These results suggest that the loss of IGLEs extends at least as far 

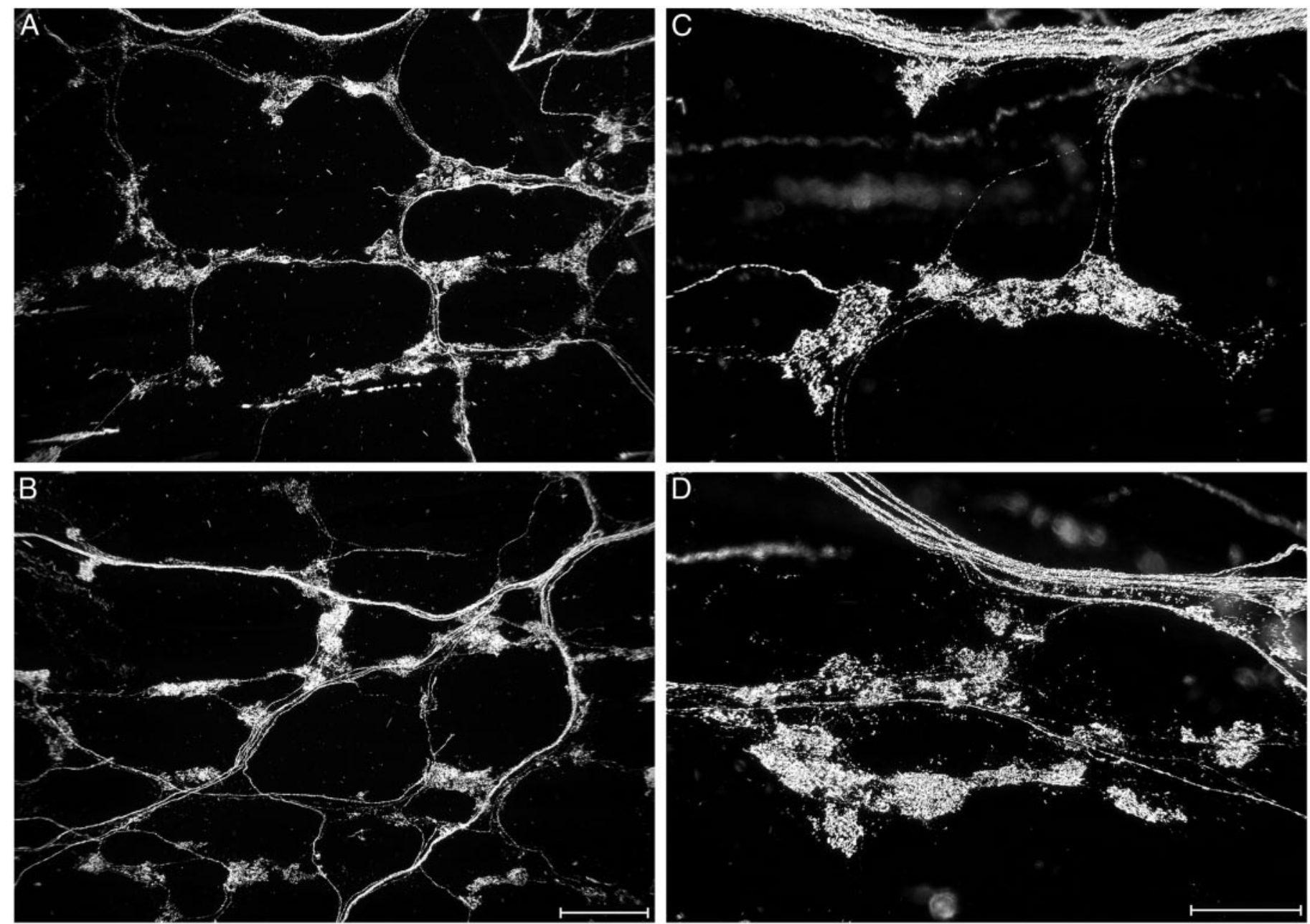

Figure 6. The morphology of IGLEs in the stomach. IGLE morphology in the stomach as labeled by WGA-HRP was similar in wild-type ( $A$, $C$ ) and NT-4 mutant mice $(B, D)$. Groups of IGLEs distribute from axons that arise from nearby fiber bundles. $A$ and $B$ are low-magnification (scale bar, 200 $\mu \mathrm{m}$ ), whereas $C$ and $D$ are high-magnification (scale bar, $100 \mu \mathrm{m}$ ) darkfield photomicrographs of IGLEs from the stomach corpus.

caudal as the ileum. Because the ileum of mutants contained labeled IGLEs, and because the ileum lies further from the injection site than does the duodenum, a deficit in the rate of WGA-HRP transport is not likely to account for the devastation of intestinal vagal sensory innervation that occurred in NT-4 mutants.

\section{Loss of intestinal IGLEs produced by NT-4 deficiency was not associated with a significant loss of myenteric neurons}

The intimate relationship between IGLEs and myenteric neurons in wild-type mice raises the possibility that the loss of most IGLEs from the myenteric ganglia of the small intestine of NT-4 mutants might lead to failed differentiation or development of the subpopulation of myenteric neurons that are normally closely apposed to IGLEs. The potential for such a trophic or functional relationship between IGLEs and myenteric neurons is supported by the presence of several peptide neurotransmitters in vagal afferents that include IGLEs (Zhuo et al., 1997), by electron microscope evidence for synaptic contacts between IGLEs and myenteric neurons (Neuhuber, 1987), and by the presence of neurotrophins and their receptors in both vagal afferents (Ernfors et al., 1992; Wetmore and Olson, 1995; Zhuo and Helke, 1996; Helke et al., 1998; Zhou et al., 1998) and the myenteric plexus
(Saffrey and Burnstock, 1994; Esteban et al., 1998; Zhou et al., 1998; Lommatzsch et al., 1999; De Giorgio et al., 2000). Therefore, the distribution and regional densities of myenteric neurons stained with cuprolinic blue were characterized in the forestomach, corpus, antrum, duodenum, and ileum of wild-type and NT-4 mutant mice to determine whether such a loss occurred. Although there were trends toward reduced myenteric neuron numbers in the duodenum (13\%) and the antrum (40\%) of mutants, they were not significant (Figs. 5B, 9C).

\section{Bundles of afferent fibers in the duodenum muscle wall were substantially reduced in NT-4 mutants}

Injection of WGA-HRP into the left nodose ganglion of NT-4 mutants and wild- type mice produced dense labeling of sensory axons in the WGA-HRP-labeled whole mounts that permitted visualization of their distribution patterns adjacent to and within the subdiaphragmatic esophagus, lower esophageal sphincter (LES), stomach, pylorus, and duodenum. In wild-type mice, these distributions were similar to the patterns in C57 mice as previously reported (Fox et al., 2000). This innervation pattern was also similar in NT-4 mutant mice in the esophagus and most regions of the stomach. However, WGA-HRP-labeled fiber bundles in the duodenum were sparse in the mutants, and the few bundles present were often smaller in diameter than is typical 

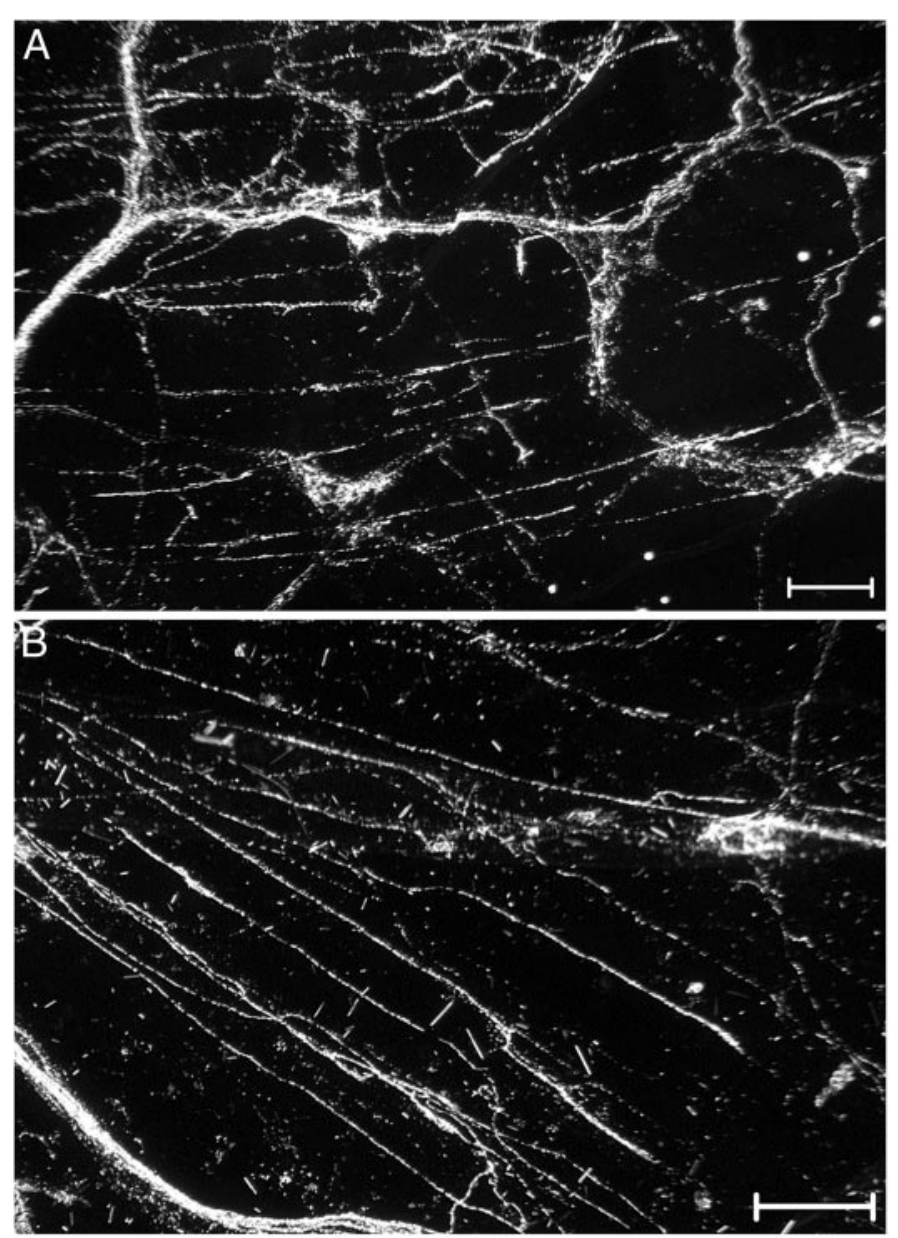

C

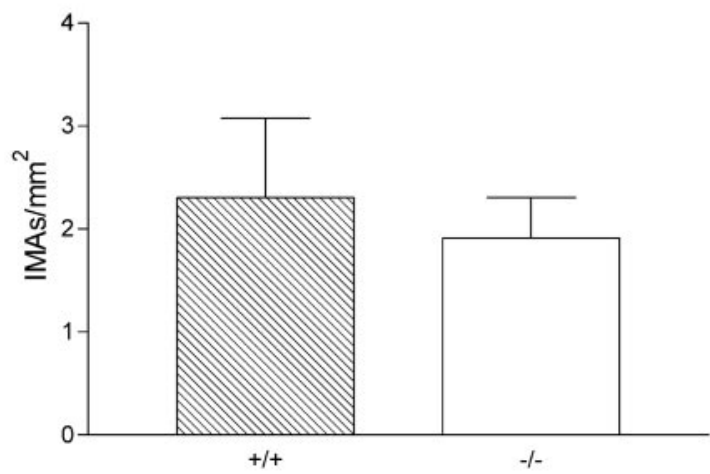

Figure 7. IMA morphology and density in the stomach were similar in wild-type and NT-4-deficient mice. $A, B$, Darkfield photomicrographs from the forestomachs in the region of peak circular IMA density of a wild-type $(A)$ and an NT-4 mutant $(B)$ mouse illustrate the similar densities of circular IMAs (labeled with WGA-HRP) that were observed in each group of mice. The IMAs are the largely rectilinear processes that sweep across the image (oriented horizontally and diagonally). A small number of sensory axon bundles and IGLEs are also present. Scale bars, $100 \mu \mathrm{m}$. $C$, Graph of circular IMA density in the stomach. There was no difference between NT-4 mutants and controls (unpaired $t$ test; $p=0.66$ ).

(Fig. 11, compare $A, B$ ). This dramatic $79 \%$ loss of vagal sensory axon bundles limited to the small intestine (mean bundle density, wild type, $22.03 \pm 1.55 / \mathrm{mm}^{2}$; NT-4 mutant, $4.6 \pm 1.3 / \mathrm{mm}^{2} ; p=$ 0.00014; two-way ANOVA, repeated measures over rostral-caudal duodenum levels) is consistent with the loss of mechanore-
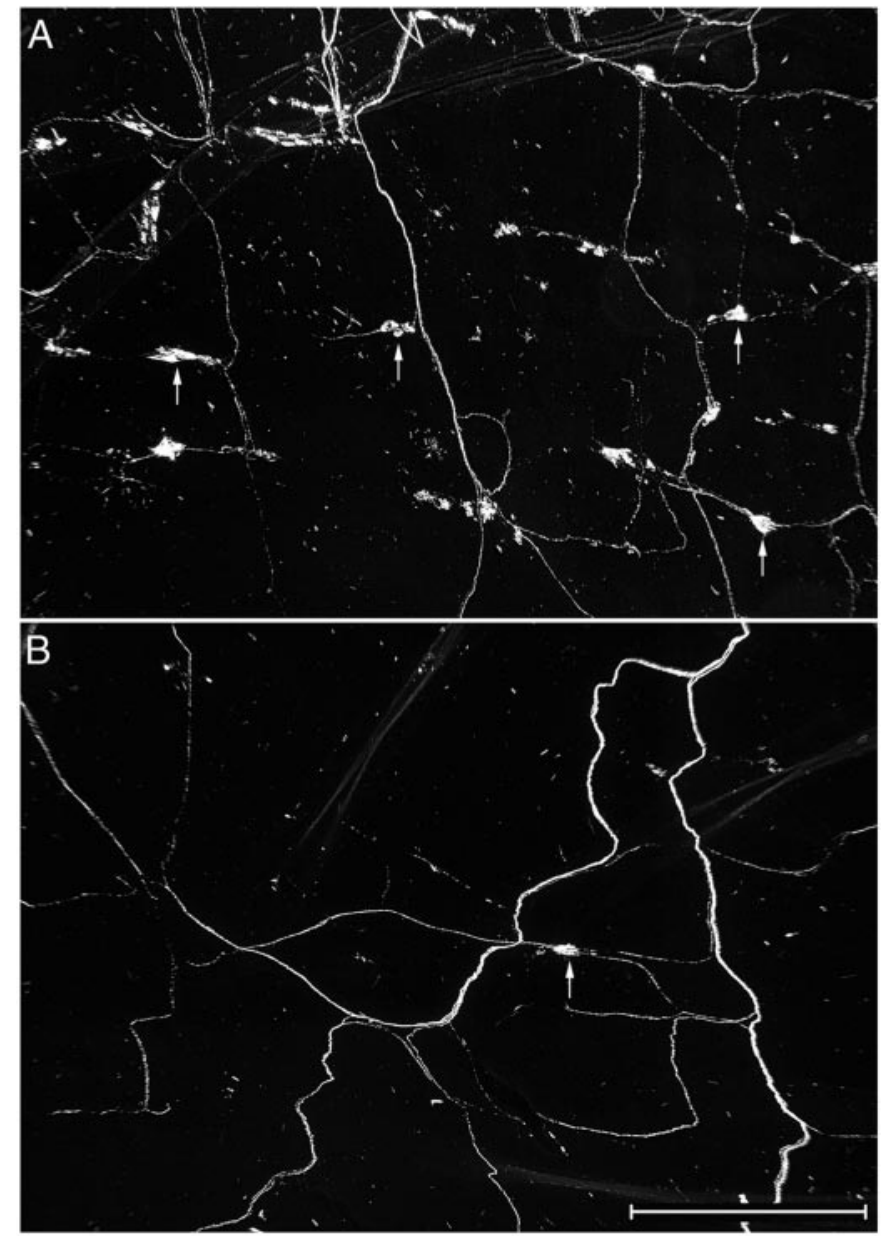

Figure 8. There was a substantial loss of IGLEs in the duodenum of NT-4-deficient mice. Low-magnification darkfield photomicrograph of IGLEs labeled with WGA-HRP (some IGLEs are identified by arrows) in a wild-type $(A)$ and an NT-4 mutant $(B)$ mouse. Each field is located in the same region of the duodenum, a region that normally has a high density of IGLEs. Only one labeled IGLE is present in this region of a mutant duodenum $(B)$. Scale bar, $0.5 \mathrm{~mm}$.

ceptors focused there. Because the majority of vagal afferents innervating the mucosa also course through the myenteric plexus connectives, the scarcity of axons in the muscle wall suggests the possibility that the NT-4 knock-out eliminates vagal afferents to the mucosa as well as to the muscle wall. Further work will be necessary to determine the status of this mucosal innervation.

\section{NT-4-deficient mice have a selective feeding deficit in regulation of meal duration}

The present finding of near complete organ-specific vagal deafferentation in NT-4-deficient mice provided a unique opportunity to explore the role of IGLE innervation of the small intestine in regulation of ingestive behavior, potentially without the confound of vagal efferent damage. Therefore, meal pattern analyses were used to assess the effects of IGLE loss in the intestine on food intake patterns. Several parameters were assessed daily for 2 weeks in NT-4 mutant and control mice fed balanced and nutritionally complete solid or liquid diets. These measures included first meal size (intake during initial 30 min of dark phase after a $6 \mathrm{hr}$ fast during lights-on), meal size, meal duration, meal frequency, intermeal interval, intake rate, and body weight. The data are presented as averages of these measures over the last $6 \mathrm{~d}$ of 

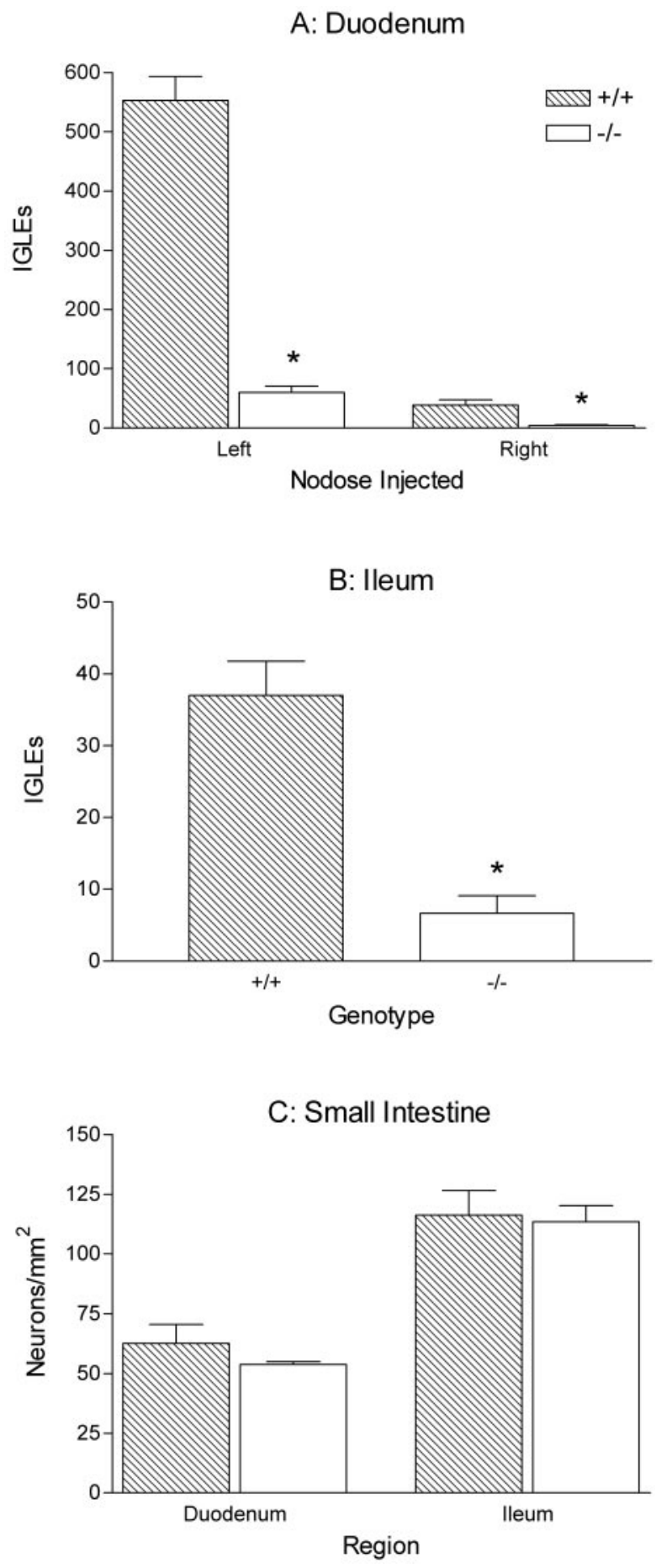

Figure 9. Quantification of IGLEs and myenteric neurons in the duodenum and ileum of wild-type and NT-4-deficient mice $\left({ }^{*} p<0.05\right) . A$, Graph of the counts of IGLEs in the duodenum of mutants and controls after WGA-HRP injections in either the left or the right nodose ganglion illustrate the substantial IGLE loss in NT-4-deficient mice $(90 \% ; t$ test; left nodose injections, $p<0.0001$; right nodose injections, $p=0.0031$ ). Neurons in the left nodose ganglion supply the majority of the IGLE innervation of the duodenum. $B$, IGLE counts in the ileum of mutants and controls after right nodose ganglion injections $(81 \%$ loss in mutants; $t$ test; $p=0.0002)$. $C$, Graph of the density of cuprolinic blue-stained myenteric neurons in the duodenum and ileum. There were no significant differences between mutants and controls ( $t$ tests, duodenum, $p=0.31$; ileum, $p=0.83)$.
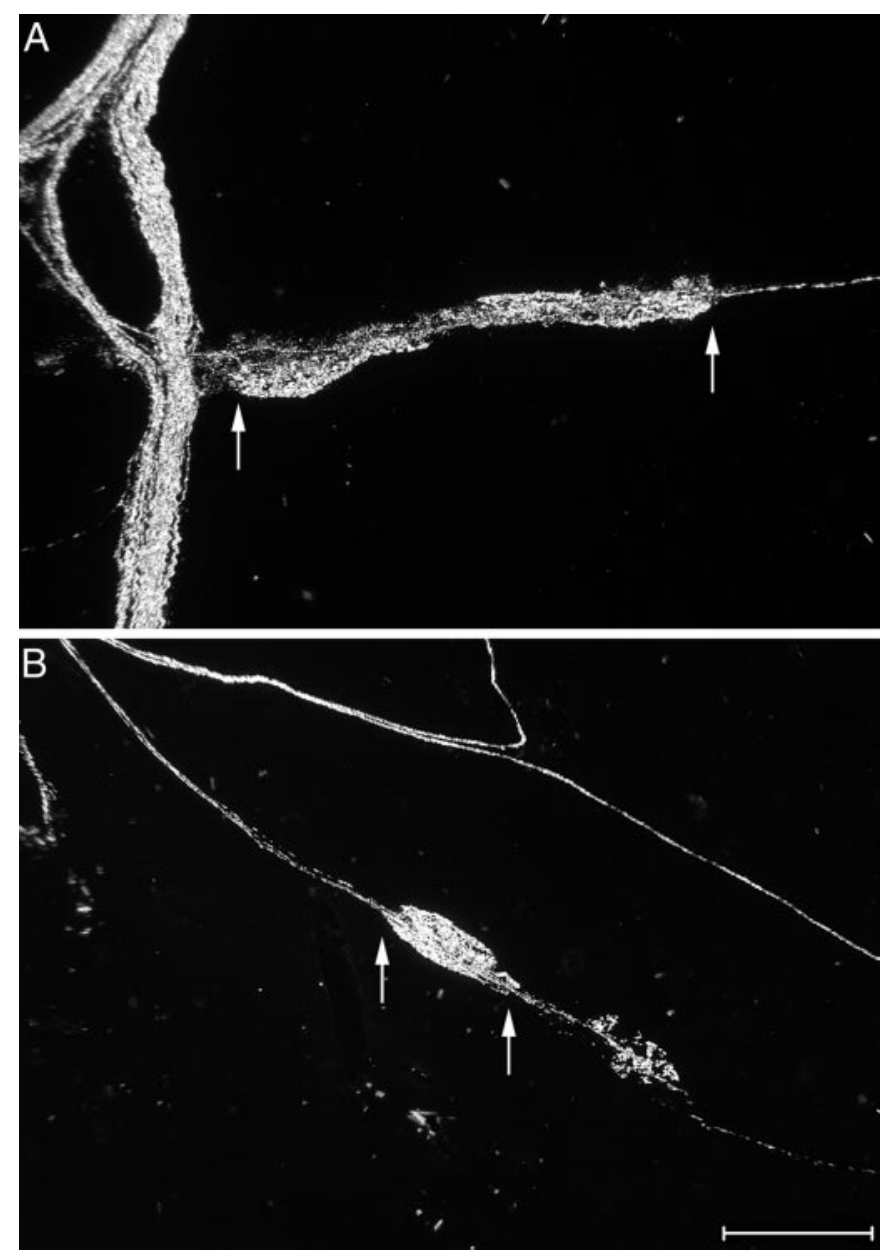

Figure 10. Morphology of IGLEs in the small intestine of wild-type and NT-4 mutant mice. High-magnification darkfield photomicrographs of IGLEs labeled with WGA-HRP (each pair of arrows indicates the extent of long axis of the dense terminal puncta that comprise one IGLE) in the duodenum of a wild-type ( $A$, oriented horizontally) and an NT-4deficient ( $B$, oriented diagonally) mouse. In $A$, a dense bundle of labeled axons courses vertically at the left of the image. In $B$, a single axon running diagonally gives rise to the IGLE and then continues on; additional axons course diagonally above the IGLE. Scale bar, $100 \mu \mathrm{m}$.

testing (days 9-14) to ensure that the food intake patterns had stabilized so that the influence of any potential differences in learning ability between mutants and controls (Xie et al., 2000) would be minimized. The significant effects are graphed, and the nonsignificant data that are described are presented in Table 2.

The majority of the food intake parameters characterized were similar in wild-type and NT-4 mutant mice. The most prominent difference that was observed was a significant $76 \%$ increase in meal duration in the NT-4-deficient mice tested with the solid $\operatorname{diet}(p=0.01)$ (Fig. 12A). Despite this dramatic increase in meal duration, there was no consistent increase in meal size in the mutants and no difference in total daily intake or body weight between mutants and wild types. Examination of the other parameters measured suggested that the increased meal duration was offset by the combination of two nonsignificant trends: a small decrease in meal frequency (mutants ate one or two meals less per day than controls), and a decrease in the average rate of intake for NT-4-deficient mice (25-40\%) compared with wild-type mice on most days. Consistent with this explanation, the average inter- 


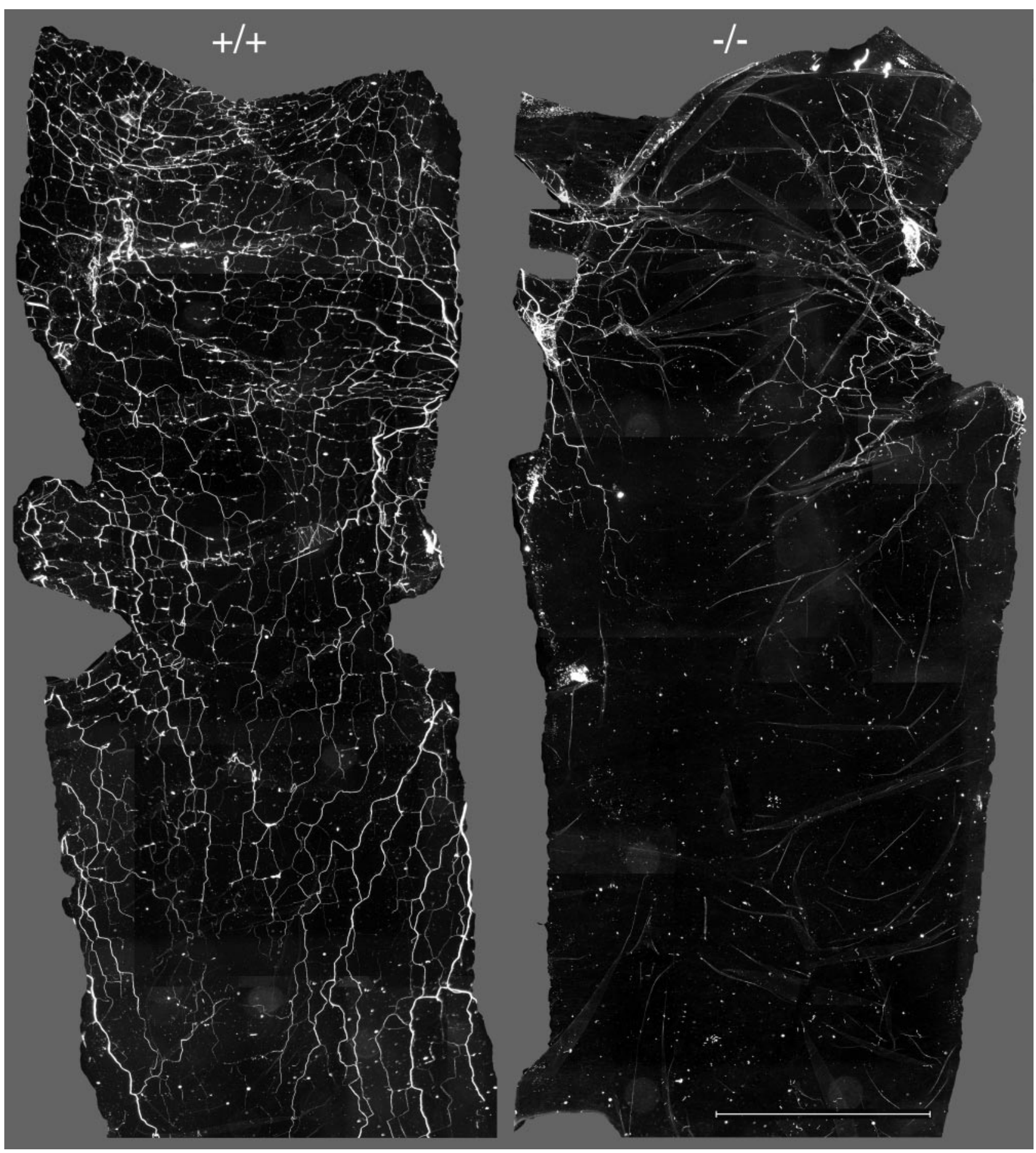

Figure 11. Photomontages of the anterior portion of the duodenums from a wild-type $(+/+)$ and an NT-4-deficient $(-/-)$ mouse. The top of each montage is the anterior end of the duodenum that was separated from the pylorus. There was substantial loss of WGA-HRP-labeled sensory axon bundles that innervate the small intestine of NT-4 mutant mice. Interestingly, quantitative analysis showed that this decreased bundle density (79\% overall) was smallest in the first centimeter of the duodenum (65\%) and became progressively larger more caudally (100\% loss in the third centimeter). Scale bar, $4.5 \mathrm{~mm}$.

meal intervals were virtually identical for mutants and controls, suggesting that they each ate to the same level of satiation.

In contrast, the significant differences that were observed in mice tested with the liquid diet were a small increase in average meal size in mutants that developed over the last six test days $(p=0.007)$ (Fig. 12B) and a moderate increase in the first meal size in mutants $(p=0.04)$ (Fig. 12C). However, the resulting trend toward increased daily total intake was not significant, and body weights were nearly identical in mutants and controls. The only change in meal parameters that might account then for the increased meal size was a small, nonsignificant increase in rate of intake that occurred during the last $6 \mathrm{~d}$. Consistent with this possibility, the significantly larger first meal size for mutants indicates that for at least the first $30 \mathrm{~min}$ after the start of food 
Table 2. Meal pattern parameters (mean \pm SEM) for pellet diet (wild-type, $n=15$; mutant, $n=15$ ) and liquid diet (wild-type, $n=12$; mutant, $n=12)$

\begin{tabular}{|c|c|c|c|c|}
\hline & \multicolumn{2}{|l|}{ Pellet diet } & \multicolumn{2}{|l|}{ Isocal liquid diet } \\
\hline & Wild-type $(+/+)$ & Mutant $(-/-)$ & Wild-type $(+/+)$ & Mutant $(-/-)$ \\
\hline Body weight (gm) & $26.6 \pm 0.96$ & $25.4 \pm 0.75$ & $25.6 \pm 0.78$ & $25.5 \pm 0.94$ \\
\hline Total intake ${ }^{a}$ & $166.1 \pm 5.3$ & $159.7 \pm 9.3$ & $11.32 \pm 0.34$ & $12.37 \pm 0.47$ \\
\hline Meal size ${ }^{a}$ & $14.91 \pm 0.64$ & $18.56 \pm 2.25$ & \multicolumn{2}{|c|}{ see Fig. $12 B$} \\
\hline Meal duration (min) & \multicolumn{2}{|c|}{ see Fig. $12 A$} & $17.2 \pm 1.75$ & $18.6 \pm 1.75$ \\
\hline Meal frequency ${ }^{b}$ & $11.7 \pm 2.3$ & $9.9 \pm 0.8$ & $17.8 \pm 0.5$ & $16.8 \pm 0.7$ \\
\hline Intake rate ${ }^{c}$ & $1.7 \pm 0.17$ & $1.23 \pm 0.16$ & $42.3 \pm 0.4$ & $47.1 \pm 0.5$ \\
\hline Intermeal interval (min) & $61.97 \pm 1.7$ & $61.54 \pm 3.3$ & $42.02 \pm 1.3$ & $39.61 \pm 1.1$ \\
\hline
\end{tabular}

Each measure was averaged daily. The tabled values are based on the average of these daily values over the last $6 \mathrm{~d}$ of behavioral testing (days 9-14).

${ }^{a}$ Number of pellets.

${ }^{b}$ Number of meals.

${ }^{c}$ Pellet diet, pellets per minute; Isocal diet, milligrams of Isocal per minute.

exposure each day their intake rate was greater than for wild types.

These meal pattern results indicate that in the absence of vagal IGLE innervation of the small intestine, specific components of short-term regulation of ingestive behavior are disrupted, whereas long-term regulation of ingestion and body weight appear to remain intact. Moreover, the differences in the nature of the meal parameters altered in NT-4-deficient mice consuming solid versus liquid diets suggest that consumption of solid and liquid foods are regulated differentially or that their regulation may depend on different signals.

\section{DISCUSSION}

NT-4-deficient mice have a dramatic reduction in IGLEs that is restricted to the small intestine. To our knowledge this is the first identification of the vagal sensory pathway and target organ affected in NT-4 mutants. The absence of intestinal IGLEs is associated with specific deficits in short-term satiety.

Vagal sensory loss in NT-4 mutants is organ-specific

Mapping of vagal mechanoreceptor innervation of the upper GI tract revealed that the loss of vagal mechanoreceptors was restricted to IGLEs in the small intestine. An organ-specific loss associated with a neurotrophin deficiency also occurs in BDNF mutants; arterial chemoreceptors in the carotid body and baroreceptors (a class of mechanoreceptor) in the carotid sinus are both lost (Erickson et al., 1996; Brady et al., 1999). Because receptors of two modalities, but of the same organ system (arterial beds), were affected, Erickson et al. (1996) and Brady et al. (1999) proposed that individual neurotrophins regulate autonomic sensory innervation of organ systems or tissues. In contrast, within the somatosensory system, each neurotrophin may predominantly regulate development of neurons subserving particular sensory modalities (Davies, 1987; Snider, 1994; Lewin, 1996).

Beyond the vagal losses identified in the present experiment, no evidence for extensive deficits in the extrinsic innervation of the GI tract has been reported for NT-4 mutants. Partial losses (20-30\%) of sympathetic preganglionic neurons in the spinal cord intermediolateral column that innervate the stellate and celiac ganglia and adrenal medulla have been identified in NT-4 mutants (Schober et al., 1998; Roosen et al., 2001). However, it has not been determined whether any postganglionics innervating the GI tract are affected. Even if these effects were more substantial, though, it is unlikely they would influence the spontaneous feeding characterized in the present study, because elimination of sympathetic innervation of the upper GI tract does not significantly alter food intake (Lorenz et al., 1982; Deutsch and Jang Ahn, 1986; Smith, 1998).

With regard to the enteric nervous system, the present observation of a trend toward reduction of myenteric neurons raises the possibility that NT-4 loss affects these neurons. We speculate that if myenteric neuron loss occurs, it is secondary to IGLE loss because IGLEs are probably absent before target innervation (see below). This loss may have been modest because only a subpopulation of myenteric neurons are contacted by IGLEs and because nonvagal neural inputs that contact myenteric neurons may be sufficient to maintain some of the myenteric neurons that lose their IGLE input.

\section{Mechanoreceptor loss in NT-4-deficient mice may occur before target innervation}

NT-4 supports cultured developing nodose ganglion neurons (Hertzberg et al., 1994) and induces neurite outgrowth from the cultured adult nodose ganglion (Wiklund and Ekstrom, 2000). Moreover, NT-4 mRNA is expressed at least as early as E13 (earliest time point examined) in visceral tissues (Timmusk et al., 1993), including some traversed by the axons of the nodose ganglion neurons growing down to the GI tract. Therefore, loss of NT-4 from the ganglion, from along the nerve trajectory between the ganglion and the target tissue, or from the target tissue could result in nodose neuron death.

Most neuronal loss from the nodose ganglion of NT-4 mutants occurs rapidly between E12 and E14 (ElShamy and Ernfors, 1997). At E13, small numbers of developing vagal axons and terminals in normal mouse embryos have begun to invade the muscle walls of the abdominal esophagus and stomach, and terminals with IGLE-like structure are already present (Sang and Young, 1998). It is not known precisely when growing axons extend into the intestine, but even if they are not present there by E13, the initial wave of growing axons should reach the intestine soon after E13. Because the period of death of NT-4-dependent neurons (or their precursors) occurs immediately before and during the time course of GI tract innervation, it is probable that intestinal IGLE innervation is lost either before, or shortly after axons reach the intestine. A similar loss before target innervation has been observed for some of the dorsal root ganglion subpopulations dependent on NT-3, for example skeletal muscle proprioceptor neurons (Kucera et al., 1995; ElShamy and Ernfors, 1996; 


\section{A: Average Meal Duration}

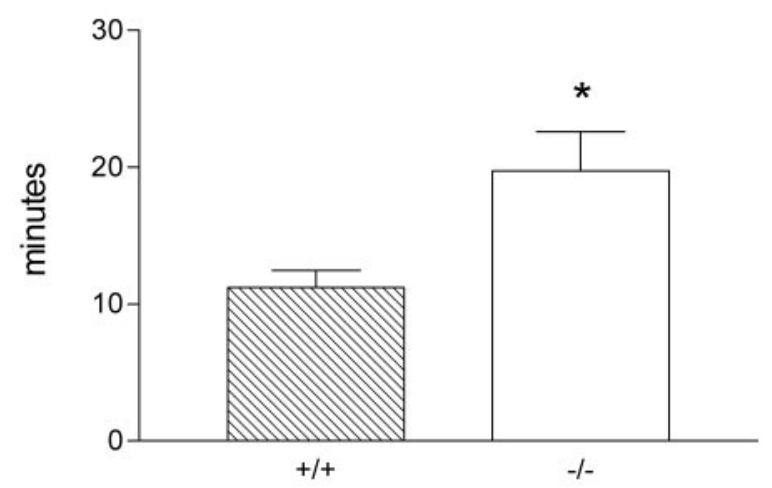

B: Average Meal Size

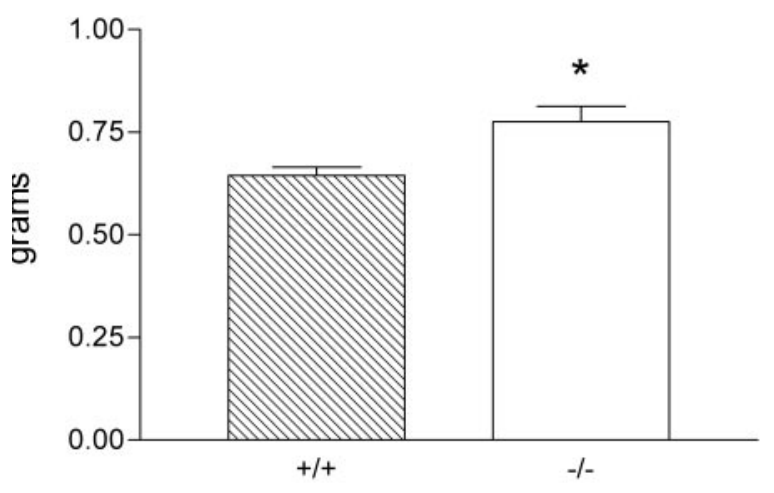

\section{C: First Meal Size}

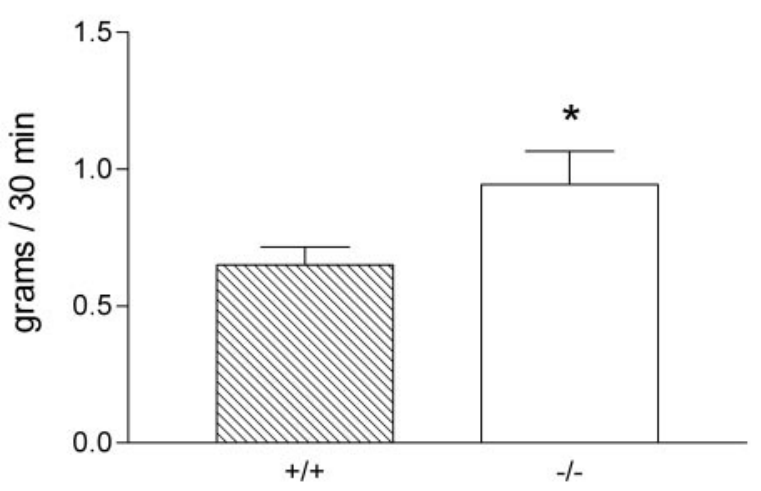

Figure 12. Short-term satiety was disrupted in NT-4 mutant mice as shown in graphs of the meal parameters that were significantly different between mutants and controls $\left({ }^{*} p<0.05\right)$. Two-way ANOVA with repeated measures over days was used for all comparisons. $A$, Meal duration was almost doubled in mutants relative to controls consuming a solid pellet diet $(p=0.01)$. $B$, Average meal size was $\sim 10 \%$ larger in NT-4-deficient mice consuming the Isocal liquid diet $(p=0.007)$. $C$, First meal size was $\sim 50 \%$ larger in NT-4 mutants compared with wild-type mice $(p=0.04)$ consuming the liquid diet, indicating that the rate of intake of mutants was higher during the first $30 \mathrm{~min}$ of food exposure each day.

Farinas et al., 1996; Liebl et al., 1997). The small number of intestinal IGLEs that remain in NT-4-deficient mice may represent a subpopulation that is not solely dependent on NT-4, or these spared endings may be the result of a developmental process that converts undifferentiated nerve terminals into IGLEs.

\section{Differential survival of gastric and intestinal IGLEs in NT-4-deficient mice}

NT-4 deficiency had virtually no effect on IGLEs in the stomach, despite their devastation in the adjacent small intestine. Interestingly, in a similar vein, there are two classes of cutaneous mechanoreceptors with similar structures, but only one of these classes (D-hair afferents) is lost in NT-4 mutants (the intact class may correspond to rapidly adapting afferents) (Stucky et al., 1998). Several mechanisms could account for differential survival of gastric and intestinal mechanoreceptors. The timetables for neurotrophin dependency of nodose cells and for their target innervation may favor survival of more proximal IGLEs (i.e., gastric). For instance, gastric afferents are more likely than intestinal ones to reach their target organ before nodose cell death (see above), and therefore have more opportunity to be rescued by a targetderived factor other than NT-4. BDNF, for example, might be able to compensate for NT-4 loss. BDNF and NT-4 share the same high-affinity receptor, trkB, and BDNF is present in the muscle wall of the GI tract (Hoehner et al., 1996; Lommatzsch et al., 1999). The shared trkB receptor underlies the ability of BDNF and NT-4 to substitute for one another to promote survival of nodose ganglion neurons in vitro (Davies et al., 1993; Ibanez et al., 1993; Buj-Bello et al., 1994; Hertzberg et al., 1994; Thaler et al., 1994), and of NT-4 to substitute for some BDNF functions in vivo, including normalizing the loss of nodose neurons in BDNF knock-out mice (Fan et al., 2000). Alternatively, gastric and intestinal IGLEs may represent different receptor phenotypes with different properties that influence their survival in the absence of NT-4. For instance, gastric and intestinal IGLEs might have different neurotrophin dependencies (e.g., gastric IGLE neurons might be among the BDNF-dependent pool of nodose cells) (Conover et al., 1995; Liu et al., 1995; Erickson et al., 1996; ElShamy and Ernfors, 1997) or neurochemical properties (e.g., gastric and intestinal IGLEs are differentially sensitive to capsaicin) (Berthoud et al., 1997b).

\section{Loss of vagal IGLE innervation of the small intestine disrupts regulation of short-term satiety}

NT-4 deficiency was associated with increases in meal duration with solid food and in meal size with liquid food, suggesting that the intestinal IGLE pathway contributes to regulation of shortterm intake. Despite these changes, normal total daily intakes and body weights were maintained by compensatory changes in other meal parameters (e.g., decreased intake rate and meal frequency for solid food) implying that long-term controls that govern homeostasis can operate normally in the absence of intestinal IGLEs. This is an important dissociation because it is often difficult to experimentally separate the actions of short-term controls (regulate intake in individual meals) and long-term controls (regulate intake integrated over many meals) in spontaneously feeding animals. For example, experimental manipulations (or pathologies) that alter feeding patterns are often associated with changes in body weight (for examples, see Kissileff et al., 1979; Strohmayer and Smith, 1987), and therefore the meal pattern changes attributable to the direct effect of the manipulation cannot be distinguished from the changes that result from the effects of altered body weight on long-term regulation. Based on the hypothesis that IGLEs transduce muscle stretch or tension produced by distension or peristaltic contraction that occurs with accumulation of food in the duodenum, intestinal IGLE loss 
could produce the meal pattern changes observed through at least two mechanisms. One might involve loss of a negative feedback signal that is normally generated by IGLEs and sent to the CNS, in which it is integrated with other signals to contribute to meal termination. A second more indirect mechanism that could alter meal patterns might result from loss of IGLE-mediated GI reflex functions. For example, to the extent that intestinal IGLEs signal the duodenal distension that activates reflex relaxation of the proximal stomach (De Ponti et al., 1987, 1989; Azpiroz and Malagelada, 1990) or facilitates peristalsis (Schwartz and Moran, 1998), loss of this IGLE function could alter the rate of nutrient transit and absorption associated with each meal. However, as long as long-term controls were operating normally (as they appeared to be) and compensated for changes in absorption rate through alterations in the appropriate meal parameters, total daily nutrient absorption and body weight gain would remain normal. Further studies in these mice should reveal the relevant contributions of these and possibly other mechanisms. Thus, NT-4 mutants provide a valuable model for developing and testing hypotheses about the role of IGLE mechanoreceptor function in short-term control of ingestive behavior without the confound produced by parallel changes in long-term regulation.

The present results are consistent with the literature that has implicated vagally mediated negative feedback signals from the small intestine in the control of short-term satiety, including signals activated by intestinal load-distension that are probably transduced by mechanoreceptors (for examples, see Yox et al., 1991; Walls et al., 1995b; Schwartz and Moran, 1998). Most relevant are studies that used vagal lesion methods that limit the degree of vagal motor damage. Capsaicin damage to a subpopulation of unmyelinated vagal afferents results in transient overconsumption of solid and liquid diets (Chavez et al., 1997; Kelly et al., 1999), whereas destruction of all afferent axons produced by surgical lesions (that also damage efferent axons unilaterally) (Norgren and Smith, 1994; Walls et al., 1995a) results in chronic increases in meal size of a liquid diet because of longer meals and higher maintained lick rates compared with controls (Schwartz et al., 1999).

Comparison of the present results with these earlier studies suggests that the intestinal IGLE pathway transmits a specific subset of all the vagally mediated feedback signals generated during ingestion. Loss of only the intestinal IGLE component of vagal GI innervation in NT-4-deficient mice increased meal size of a liquid diet by changing only intake rate. In contrast, complete vagal deafferentation produced larger increases in meal size of a liquid diet by increasing both intake rate and meal duration (Schwartz et al., 1999). Similarly, selective loss of the intestinal IGLE pathway increased only meal duration of a solid diet, whereas partial disruption of several vagal sensory pathways with capsaicin increased both meal size and meal duration of a solid diet, albeit transiently (Chavez et al., 1997).

In summary, NT-4 knock-out mice exhibit vagal neuron losses that are specific not only to afferents but also to one class of mechanoreceptors and to intestinal projection fields of these endings. Altered meal patterns in these mice suggest that they may provide a useful model with a selective deafferentation and that intestinal IGLEs participate in the control of short-term intake.

\section{REFERENCES}

Aldskogius H, Elfvin LG, Forsman CA (1986) Primary sensory afferents in the inferior mesenteric ganglion and related nerves of the guinea pig.
An experimental study with anterogradely transported wheat germ agglutinin-horseradish peroxidase conjugate. J Auton Nerv Syst 15:179-190.

Azpiroz F, Malagelada JR (1990) Perception and reflex relaxation of the stomach in response to gut distention. Gastroenterology 98:1193-1198.

Berthoud HR, Powley TL (1992) Vagal afferent innervation of the rat fundic stomach: morphological characterization of the gastric tension receptor. J Comp Neurol 319:261-276.

Berthoud HR, Patterson LM, Neumann F, Neuhuber WL (1997a) Distribution and structure of vagal afferent intraganglionic laminar endings (IGLEs) in the rat gastrointestinal tract. Anat Embryol 195:183-191.

Berthoud HR, Patterson LM, Willing AE, Mueller K, Neuhuber WL (1997b) Capsaicin-resistant vagal afferent fibers in the rat gastrointestinal tract: anatomical identification and functional integrity. Brain Res 746:195-206.

Brady R, Zaidi SI, Mayer C, Katz DM (1999) BDNF is a target-derived survival factor for arterial baroreceptor and chemoafferent primary sensory neurons. J Neurosci 19:2131-2142.

Buj-Bello A, Pinon LG, Davies AM (1994) The survival of NGFdependent but not BDNF-dependent cranial sensory neurons is promoted by several different neurotrophins early in their development. Development 120:1573-1580.

Carobi C (1996) A quantitative investigation of the effects of neonatal capsaicin treatment on vagal afferent neurons in the rat. Cell Tissue Res 283:305-311.

Chavez M, Kelly L, York DA, Berthoud HR (1997) Chemical lesion of visceral afferents causes transient overconsumption of unfamiliar highfat diets in rats. Am J Physiol 272:R1657-1663.

Coggeshall RE, Lekan HA (1996) Methods for determining numbers of cells and synapses: a case for more uniform standards of review. J Comp Neurol 364:6-15.

Conover JC, Erickson JT, Katz DM, Bianchi LM, Poueymirou WT, McClain J, Pan L, Helgren M, Ip NY, Boland P, Friedman B, Wiegand A, Vejsada R, Kato AC, DeChiara TM, Yancopoulos GD (1995) Neuronal deficits, not involving motor neurons, in mice lacking BDNF and/or NT4. Nature 375:235-238.

Davies AM (1987) Molecular and cellular aspects of patterning sensory neurone connections in the vertebrate nervous system. Development 101:185-208.

Davies AM, Horton A, Burton LE, Schmelzer C, Vandlen R, Rosenthal A (1993) Neurotrophin-4/5 is a mammalian-specific survival factor for distinct populations of sensory neurons. J Neurosci 13:4961-4967.

De Giorgio R, Arakawa J, Wetmore CJ, Sternini C (2000) Neurotrophin-3 and neurotrophin receptor immunoreactivity in peptidergic enteric neurons. Peptides 21:1421-1426.

De Ponti F, Azpiroz F, Malagelada JR (1987) Reflex gastric relaxation in response to distention of the duodenum. Am J Physiol 252:G595-601.

De Ponti F, Azpiroz F, Malagelada JR (1989) Relaxatory responses of canine proximal stomach to esophageal and duodenal distension. Importance of vagal pathways. Dig Dis Sci 34:873-881.

Deutsch JA, Jang Ahn S (1986) The splanchnic nerve and food intake regulation. Behav Neural Biol 45:43-47.

ElShamy WM, Ernfors P (1996) Requirement of neurotrophin-3 for the survival of proliferating trigeminal ganglion progenitor cells. Development 122:2405-2414.

ElShamy WM, Ernfors P (1997) Brain-derived neurotrophic factor, neurotrophin-3, and neurotrophin-4 complement and cooperate with each other sequentially during visceral neuron development. J Neurosci 17:8667-8675.

Erickson JT, Conover JC, Borday V, Champagnat J, Barbacid M, Yancopoulos G, Katz DM (1996) Mice lacking brain-derived neurotrophic factor exhibit visceral sensory neuron losses distinct from mice lacking NT4 and display a severe developmental deficit in control of breathing. J Neurosci 16:5361-5371.

Ernfors P, Merlio JP, Persson H (1992) Cells expressing messengerRNA for neurotrophins and their receptors during embryonic rat development. Eur J Neurosci 4:1140-1158.

Ernfors P, Lee KF, Jaenisch R (1994) Mice lacking brain-derived neurotrophic factor develop with sensory deficits. Nature 368:147-150.

Esteban I, Levanti B, Garcia-Suarez O, Germana G, Ciriaco E, Naves FJ, Vega JA (1998) A neuronal subpopulation in the mammalian enteric nervous system expresses TrkA and TrkC neurotrophin receptor-like proteins. Anat Rec 251:360-370.

Fan G, Egles C, Sun Y, Minichiello L, Renger JJ, Klein R, Liu G, Jaenisch R (2000) Knocking the NT4 gene into the BDNF locus rescues BDNF deficient mice and reveals distinct NT4 and BDNF activities. Nat Neurosci 3:350-357.

Farinas I, Yoshida CK, Backus C, Reichardt LF (1996) Lack of neurotrophin-3 results in death of spinal sensory neurons and premature differentiation of their precursors. Neuron 17:1065-1078.

Fox EA, Phillips RJ, Martinson FA, Baronowsky EA, Powley TL (2000) Vagal afferent innervation of smooth muscle in the stomach and duodenum of the mouse: morphology and topography. J Comp Neurol 428:558-576. 
Fox EA, Phillips RJ, Martinson FA, Baronowsky EA, Powley TL (2001) $\mathrm{C}$-Kit mutant mice have a selective loss of vagal intramuscular mechanoreceptors that innervate gastric smooth muscle. Anat Embryol 204:11-26.

Guillery RW, Herrup K (1997) Quantification without pontification: choosing a method for counting objects in sectioned tissues. J Comp Neurol 386:2-7.

Heinicke EA, Kiernan JA, Wijsman J (1987) Specific, selective, and complete staining of neurons of the myenteric plexus, using cuprolinic blue. J Neurosci Methods 21:45-54.

Helke CJ, Adryan KM, Fedorowicz J, Z huo H, Park JS, Curtis R, Radley HE, Distefano PS (1998) Axonal transport of neurotrophins by visceral afferent and efferent neurons of the vagus nerve of the rat. J Comp Neurol 393:102-117.

Hertzberg T, Fan G, Finley JC, Erickson JT, Katz DM (1994) BDNF supports mammalian chemoafferent neurons in vitro and following peripheral target removal in vivo. Dev Biol 166:801-811.

Hoehner JC, Wester T, Pahlman S, Olsen L (1996) Localization of neurotrophins and their high-affinity receptors during human enteric nervous system development. Gastroenterology 110:756-767.

Holst MC, Powley TL (1995) Cuprolinic blue (quinolinic phthalocyanine) counterstaining of enteric neurons for peroxidase immunocytochemistry. J Neurosci Methods 62:121-127.

Ibanez CF, Ernfors P, Timmusk T, Ip NY, Arenas E, Yancopoulos GD, Persson H (1993) Neurotrophin-4 is a target-derived neurotrophic factor for neurons of the trigeminal ganglion. Development 117:1345-1353.

Jones KR, Farinas I, Backus C, Reichardt LF (1994) Targeted disruption of the BDNF gene perturbs brain and sensory neuron development but not motor neuron development. Cell 76:989-999.

Karaosmanoglu T, Aygun B, Wade PR, Gershon MD (1996) Regional differences in the number of neurons in the myenteric plexus of the guinea pig small intestine and colon: an evaluation of markers used to count neurons. Anat Rec 244:470-480.

Kelly LA, Chavez M, Berthoud HR (1999) Transient overconsumption of novel foods by deafferentated rats: effects of novel diet composition. Physiol Behav 65:793-800.

Kissileff HR, Nakashima RK, Stunkard AJ (1979) Effects of jejunoileal bypass on meal patterns in genetically obese and lean rats. Am J Physiol 237:R217-224.

Kressel M, Berthoud HR, Neuhuber WL (1994) Vagal innervation of the rat pylorus: an anterograde tracing study using carbocyanine dyes and laser scanning confocal microscopy. Cell Tissue Res 275:109-123.

Kucera J, Fan G, Jaenisch R, Linnarsson S, Ernfors P (1995) Dependence of developing group Ia afferents on neurotrophin-3. J Comp Neurol 363:307-320.

Lewin GR (1996) Neurotrophins and the specification of neuronal phenotype. Philos Trans R Soc Lond B Biol Sci 351:405-411.

Liebl DJ, Tessarollo L, Palko ME, Parada LF (1997) Absence of sensory neurons before target innervation in brain-derived neurotrophic factor-, neurotrophin 3-, and TrkC-deficient embryonic mice. J Neurosci 17:9113-9121.

Liu X, Ernfors P, Wu H, Jaenisch R (1995) Sensory but not motor neuron deficits in mice lacking NT4 and BDNF. Nature 375:238-241.

Lommatzsch M, Braun A, Mannsfeldt A, Botchkarev VA, Botchkareva NV, Paus R, Fischer A, Lewin GR, Renz H (1999) Abundant production of brain-derived neurotrophic factor by adult visceral epithelia. Implications for paracrine and target-derived neurotrophic functions. Am J Pathol 155:1183-1193.

Lorenz DN, Ellis SB, Epstein AN (1982) Differential effects of upper gastrointestinal fill on milk ingestion and nipple attachment in the suckling rat. Dev Psychobiol 15:309-330.

Mesulam MM (1978) Tetramethyl benzidine for horseradish peroxidase neurohistochemistry: a non-carcinogenic blue reaction product with superior sensitivity for visualizing neural afferents and efferents. J Histochem Cytochem 26:106-117.

Neuhuber WL (1987) Sensory vagal innervation of the rat esophagus and cardia: a light and electron microscopic anterograde tracing study. J Auton Nerv Syst 20:243-255.

Nonidez JF (1946) Afferent nerve endings in the ganglia of the intermuscular plexus of the dog's esophagus. J Comp Neurol 85:177-185.

Norgren R, Smith GP (1994) A method for selective section of vagal afferent or efferent axons in the rat. Am J Physiol 267:R1136-1141.

Phillips RJ, Powley TL (2000) Tension and stretch receptors in gastrointestinal smooth muscle: re-evaluating vagal mechanoreceptor electrophysiology. Brain Res Brain Res Rev 34:1-26.

Phillips RJ, Baronowsky EA, Powley TL (1997) Afferent innervation of gastrointestinal tract smooth muscle by the hepatic branch of the vagus. J Comp Neurol 384:248-270.

Powley TL, Holst MC, Boyd DB, Kelly JB (1994) Three-dimensional reconstructions of autonomic projections to the gastrointestinal tract. Microsc Res Tech 29:297-309.
Rodrigo J, Hernandez J, Vidal MA, Pedrosa JA (1975) Vegetative innervation of the esophagus. II. Intraganglionic laminar endings. Acta Anat 92:79-100.

Rodrigo J, de Felipe J, Robles-Chillida EM, Perez Anton JA, Mayo I, Gomez A (1982) Sensory vagal nature and anatomical access paths to esophagus laminar nerve endings in myenteric ganglia. Determination by surgical degeneration methods. Acta Anat 112:47-57.

Roosen A, Schober A, Strelau J, Bottner M, Faulhaber J, Bendner G McIlwrath SL, Seller H, Ehmke H, Lewin GR, Unsicker K (2001) Lack of neurotrophin-4 causes selective structural and chemical deficits in sympathetic ganglia and their preganglionic innervation. J Neurosci 21:3073-3084.

Saffrey MJ, Burnstock G (1994) Growth factors and the development and plasticity of the enteric nervous system. J Auton Nerv Syst 49:183-196.

Sang Q, Young HM (1998) The origin and development of the vagal and spinal innervation of the external muscle of the mouse esophagus. Brain Res 809:253-268.

Schober A, Wolf N, Huber K, Hertel R, Krieglstein K, Minichiello L, Kahane N, Widenfalk J, Kalcheim C, Olson L, Klein R, Lewin GR Unsicker K (1998) TrkB and neurotrophin-4 are important for development and maintenance of sympathetic preganglionic neurons innervating the adrenal medulla. J Neurosci 18:7272-7284.

Schwartz GJ, Moran TH (1998) Duodenal nutrient exposure elicits nutrient-specific gut motility and vagal afferent signals in rat. Am J Physiol 274:R1236-1242.

Schwartz GJ, Salorio CF, Skoglund C, Moran TH (1999) Gut vagal afferent lesions increase meal size but do not block gastric preloadinduced feeding suppression. Am J Physiol 276:R1623-1629.

Smith GP (1998) Pregastric and gastric satiety. In: Satiation: from gut to brain (Smith GP, ed), pp 10-39. New York: Oxford UP.

Smith GP, Jerome C, Norgren R (1985) Afferent axons in abdominal vagus mediate satiety effect of cholecystokinin in rats. Am J Physiol 249:R638-641.

Snider WD (1994) Functions of the neurotrophins during nervous system development: what the knockouts are teaching us. Cell 77:627-638

Strohmayer AJ, Smith GP (1987) The meal pattern of genetically obese (ob/ob) mice. Appetite 8:111-123.

Stucky CL, DeChiara T, Lindsay RM, Yancopoulos GD, Koltzenburg M (1998) Neurotrophin 4 is required for the survival of a subclass of hair follicle receptors. J Neurosci 18:7040-7046.

Thaler CD, Suhr L, Ip N, Katz DM (1994) Leukemia inhibitory factor and neurotrophins support overlapping populations of rat nodose sensory neurons in culture. Dev Biol 161:338-344.

Timmusk T, Belluardo N, Metsis M, Persson H (1993) Widespread and developmentally regulated expression of neurotrophin-4 mRNA in rat brain and peripheral tissues. Eur J Neurosci 5:605-613.

Walls EK, Wang FB, Holst MC, Phillips RJ, Voreis JS, Perkins AR, Pollard LE, Powley TL (1995a) Selective vagal rhizotomies: a new dorsal surgical approach used for intestinal deafferentations. Am J Physiol 269:R1279-1288.

Walls EK, Phillips RJ, Wang FB, Holst MC, Powley TL (1995b) Suppression of meal size by intestinal nutrients is eliminated by celiac vagal deafferentation. Am J Physiol 269:R1410-1419.

Wang FB, Powley TL (2000) Topographic inventories of vagal afferents in gastrointestinal muscle. J Comp Neurol 421:302-324.

Wetmore C, Olson L (1995) Neuronal and nonneuronal expression of neurotrophins and their receptors in sensory and sympathetic ganglia suggest new intercellular trophic interactions. J Comp Neurol 353:143-159.

Wiklund P, Ekstrom PA (2000) Axonal outgrowth from adult mouse nodose ganglia in vitro is stimulated by neurotrophin-4 in a Trk receptor and mitogen-activated protein kinase-dependent way. J Neurobiol 45:142-151.

Xie CW, Sayah D, Chen QS, Wei WZ, Smith D, Liu X (2000) Deficient long-term memory and long-lasting long-term potentiation in mice with a targeted deletion of neurotrophin-4 gene. Proc Natl Acad Sci USA 97:8116-8121.

Yox DP, Stokesberry H, Ritter RC (1991) Vagotomy attenuates suppression of sham feeding induced by intestinal nutrients. Am J Physiol 260:R503-508.

Zagorodnyuk VP, Brookes SJ (2000) Transduction sites of vagal mechanoreceptors in the guinea pig esophagus. J Neurosci 20:6249-6255.

Zhuo H, Helke CJ (1996) Presence and localization of neurotrophin receptor tyrosine kinase (TrkA, TrkB, TrkC) mRNAs in visceral afferent neurons of the nodose and petrosal ganglia. Brain Res Mol Brain Res 38:63-70.

Zhuo H, Ichikawa H, Helke CJ (1997) Neurochemistry of the nodose ganglion. Prog Neurobiol 52:79-107.

Zhou XF, Chie ET, Rush RA (1998) Distribution of brain-derived neurotrophic factor in cranial and spinal ganglia. Exp Neurol 149:237242 